University of Nebraska - Lincoln

DigitalCommons@University of Nebraska - Lincoln

Drought Mitigation Center Faculty Publications Drought -- National Drought Mitigation Center

$10-14-2013$

\title{
Examining the Relationship between Drought Development and Rapid Changes in the Evaporative Stress Index
}

Jason A. Otkin

Martha C. Anderson

Christopher Hain

Mark D. Svoboda

Follow this and additional works at: https://digitalcommons.unl.edu/droughtfacpub

Digitairt of the Climate Commons, Environmental Indicators and Impact Assessment Commons, Epmmpnental Monitoring Commons, Hydrology Commons, Other Earth Sciences Commons, and the Nettereresource Management Commons

Logo

This Article is brought to you for free and open access by the Drought -- National Drought Mitigation Center at DigitalCommons@University of Nebraska - Lincoln. It has been accepted for inclusion in Drought Mitigation Center Faculty Publications by an authorized administrator of DigitalCommons@University of Nebraska - Lincoln. 


\title{
${ }^{\partial}$ Examining the Relationship between Drought Development and Rapid Changes in the Evaporative Stress Index
}

\author{
JASON A. OTKIN \\ Cooperative Institute for Meteorological Satellite Studies, University of Wisconsin-Madison, Madison, Wisconsin \\ MARTHA C. ANDERSON \\ Hydrology and Remote Sensing Laboratory, Agricultural Research Services, U.S. Department of Agriculture, Beltsville, Maryland \\ CHRISTOPHER HAIN \\ Earth System Interdisciplinary Center, University of Maryland, College Park, College Park, Maryland \\ MARK SVOBODA \\ National Drought Mitigation Center, University of Nebraska-Lincoln, Lincoln, Nebraska
}

(Manuscript received 9 July 2013, in final form 14 October 2013)

\begin{abstract}
In this study, the ability of a new drought metric based on thermal infrared remote sensing imagery to provide early warning of an elevated risk for drought intensification is assessed. This new metric, called the rapid change index (RCI), is designed to highlight areas undergoing rapid changes in moisture stress as inferred from weekly changes in the evaporative stress index (ESI) generated using the Atmosphere-Land Exchange Inverse (ALEXI) surface energy balance model. Two case study analyses across the central United States revealed that the initial appearance of negative RCI values indicative of rapid increases in moisture stress preceded the introduction of severe-to-exceptional drought in the U.S. Drought Monitor (USDM) by more than 4 weeks. Using data from 2000 to 2012, the probability of USDM intensification of at least one, two, or three categories over different time periods was computed as a function of the RCI magnitude. Compared to baseline probabilities, the RCI-derived probabilities often indicate a much higher risk for drought development that increases greatly as the RCI becomes more negative. When the RCI is strongly negative, many areas are characterized by intensification probabilities that are several times higher than the baseline climatology. The highest probabilities encompass much of the central and eastern United States, with the greatest increase over climatology within regions most susceptible to rapid drought development. These results show that the RCI provides useful drought early warning capabilities that could be used to alert stakeholders of an increased risk for drought development over subseasonal time scales.
\end{abstract}

\section{Introduction}

Extreme drought events in recent decades have caused extensive damage to natural ecosystems and have contributed to lower agricultural productivity across large

๑ Denotes Open Access content.

Corresponding author address: Jason A. Otkin, Cooperative Institute for Meteorological Satellite Studies, University of WisconsinMadison, 1225 W. Dayton St., Madison, WI 53706.

E-mail: jason.otkin@ssec.wisc.edu areas of the United States. Because droughts collectively impact more people than any other type of natural disaster and can lead to extensive economic losses (Lott and Ross 2006), the development of robust drought early warning indicators is necessary to assist drought mitigation and climate adaptation efforts (e.g., Wilhite et al. 2000; Wilhite and Pulwarty 2005). Early warning of an increased likelihood for drought initiation and intensification from weekly to seasonal time scales can be used by vulnerable stakeholders to implement proactive mitigation measures, such as increased water conservation, preemptive culling of livestock herds, and exploration of alternative pricing strategies for grain and other farm 
products. Indeed, one of the goals of the National Integrated Drought Information System (NIDIS) is to create a drought early warning system capable of providing accurate information on current drought conditions and associated risks at spatial scales sufficient to allow users to make informed management decisions.

Although drought is often viewed as a slowly evolving climate phenomenon that requires several months or longer to reach its maximum intensity and geographic extent, its onset and development can be very rapid if extreme atmospheric anomalies remain over the same area for several weeks (Otkin et al. 2013). Intense heat waves and below-normal rainfall combined with strong winds and sunny skies can quickly deplete root zone soil moisture and lead to rapidly deteriorating vegetation health due to increasing moisture stress (Mozny et al. 2012). Because this scenario is most likely to occur during the growing season when potential evaporation is highest, agricultural interests are often most strongly affected. Significant yield loss may result if intense moisture stress occurs during crop emergence, pollination, or grain filling stages, with the combined effects of extreme heat stress and depleted soil moisture especially damaging (e.g., Rotter and van de Geijn 1999; Saini and Westgate 1999; Ciais et al. 2005; Mittler 2006; Barnabás et al. 2008; Li et al. 2009; Mishra and Cherkauer 2010; Prasad et al. 2011; Swain et al. 2011; Kebede et al. 2012; Pradhan et al. 2012).

In recent years, the term "flash drought" has been used to better distinguish rapid onset drought events from those that develop more slowly (e.g., Otkin et al. 2013; Svoboda et al. 2002). This terminology captures the distinguishing characteristic of these droughts, namely, their unusually rapid rate of intensification. However, flash droughts can also transition into longer-term hydrological drought if large moisture anomalies persist for many months. In 2011 and 2012, extreme heat and low rainfall created conditions conducive to flash drought development across parts of the central United States, with severe-to-exceptional drought conditions becoming entrenched across the region (e.g., Blunden and Arndt 2012). According to weekly drought analyses from the U.S. Drought Monitor (USDM; Svoboda et al. 2002), drought intensification was so rapid in some locations that up to a three-category increase in drought severity occurred over periods as short as 1 month. The extreme drought conditions led to widespread crop failure and large reductions in livestock populations across the south-central United States and to lower grain yields across the Midwestern Corn Belt (USDA 2012, 2013). The large agricultural losses and reduced economic output, along with increases in grassland and forest fires, the implementation of severe water restrictions, and other socioeconomic displacements, demonstrate the continued vulnerability of the United States to severe droughts.

An accurate representation of current drought conditions is a prerequisite for producing useful drought intensification forecasts. A plethora of drought indicators with varying complexity and spatiotemporal resolutions have been developed over the past several decades to monitor drought severity and its spatial extent. Often, a suite of indices is necessary to provide a comprehensive assessment of drought conditions. Two of the most widely used indices include the Palmer drought severity index (PDSI; Palmer 1965) and the standardized precipitation index (SPI; McKee et al. 1993, 1995). Precipitation is the only input to the SPI, whereas both precipitation and temperature observations are used to compute the PDSI. A new index known as the standardized precipitation evaporation index (SPEI; Vicente-Serrano et al. 2010) was designed to combine the sensitivity of the PDSI to changes in evaporative demand with the simplicity of the SPI. Sun et al. (2012) describe a multi-index drought model used to assess drought risk to spring wheat yield on the Canadian prairies using a combination of drought indices, including the SPI and PDSI. Drought indices can also be computed using model output, such as soil moisture, precipitation, and surface runoff, from the North American Land Data Assimilation System (NLDAS; Xia et al. 2012a,b; Mo 2008).

Remote sensing observations of green biomass can be used to identify areas characterized by poor plant health or reduced vegetation cover, as employed in drought indices such as the vegetation drought response index (Brown et al. 2008) and the vegetation condition index (Kogan 1990). However, plant stress during the early stages of drought development is difficult to identify using vegetation indices because signals of increasing moisture stress only become apparent after substantial damage has already occurred to the vegetation (Moran 2003). A more reliable signal of incipient drought stress may be derived using land surface temperature (LST) observations retrieved using satellite thermal infrared (TIR) imagery. As root zone soil moisture decreases, canopy temperatures rise in comparison with unstressed vegetation under the same atmospheric conditions because less energy is used for evapotranspiration (ET). The Atmosphere-Land Exchange Inverse (ALEXI; Anderson et al. 2007b) surface energy balance model uses this relationship and remotely sensed LST to estimate ET. Drought severity can be inferred from reductions in the ratio of actual to potential ET, as represented by the ALEXI-based evaporative stress index (ESI; Anderson et al. 2007c, 2011). Drought metrics such as the ESI are uniquely sensitive to rapid changes in soil moisture content and plant water usage because an energy balance 
approach accounts not only for the impact of rainfall departures, but also to temperature, radiation, and wind anomalies often associated with flash drought development (Otkin et al. 2013).

In this paper, the ability of rapid changes in the ESI to provide early warning of worsening drought conditions, as depicted by weekly USDM analyses, will be explored for the nominal growing season (April-October) during 2000-12. The fast response of the ESI to increasing moisture stress provides a fundamental opportunity for improved drought predictions from weekly to monthly time scales. Lyon et al. (2012) have recently shown that even when information on seasonal anomalies in future precipitation is unavailable, skillful drought predictions are still possible if the current drought state is accurately monitored. Knowledge of seasonal precipitation characteristics and the current drought status, combined with the inherent predictive skill associated with drought persistence, has been used to develop autoregressive models to predict future drought conditions (e.g., Mishra and Desai 2005; Sen and Boken 2005). The National Oceanic and Atmospheric Administration employs a similar approach to produce the qualitative drought outlook forecast product that identifies areas likely to experience changing drought conditions. This product is created by propagating the existing drought state as embodied by the USDM into the next season using seasonal predictions of temperature and precipitation anomalies combined with other relevant information. Here we evaluate the potential utility of a rapid change index (RCI) product designed to highlight areas undergoing rapid changes in the ESI to provide early warning of incipient or worsening drought conditions across the contiguous United States (CONUS). Section 2 contains a description of the ALEXI model and the ESI, RCI, and USDM datasets. Results are shown in section 3, with conclusions given in section 4 .

\section{Data and methodology}

\section{a. ALEXI model}

ALEXI is a two-source energy balance (TSEB) model used to compute energy fluxes for bare soil and vegetated components of the land surface (Norman et al. 1995). Remotely sensed LST observations are used to constrain the sensible heat flux, with the latent heat flux $\lambda E\left[\mathrm{~W} \mathrm{~m}^{-2}\right.$; where $E$ is ET $\left(\mathrm{mm} \mathrm{s}^{-1}\right.$ or kg s$\left.{ }^{-1} \mathrm{~m}^{-2}\right)$ and $\lambda$ is the latent heat of evaporation $\left.\left(\mathrm{J} \mathrm{kg}^{-1}\right)\right]$ computed as a residual of the overall energy balance equation. Estimates of leaf area index or vegetation cover fraction are used to partition the LST and energy fluxes between the soil and vegetation components. ALEXI infers the surface energy budget using the observed rise in LST from $\sim 1.5 \mathrm{~h}$ after local sunrise to $1.5 \mathrm{~h}$ before local noon as measured with geostationary satellites. By employing the TSEB in time differential mode, sensitivity to LST errors resulting from errors in sensor calibration and atmospheric correction is reduced (Anderson et al. 1997). A simple model of atmospheric boundary layer (ABL) growth developed by McNaughton and Spriggs (1986) provides closure to the energy balance equations over the morning integration period.

ALEXI is run daily over the CONUS with $10-\mathrm{km}$ horizontal resolution using hourly LST fields retrieved from Geostationary Operational Environmental Satellites (GOES) sounder data, vegetation cover fraction derived from the 8-day Moderate Resolution Imaging Spectroradiometer (MODIS) leaf area index product (Myneni et al. 2002), and insolation estimates from the GOES imager (Otkin et al. 2005). The ABL model also uses temperature lapse rate information from the North American Regional Reanalysis (Mesinger et al. 2006). Daily ET errors are typically less than $10 \%-15 \%$ of the mean observed flux for a variety of climate conditions and vegetation types. The reader is referred to Anderson et al. (2007a) for a complete description of the ALEXI model.

\section{b. Evaporative stress index}

The ESI represents standardized anomalies in ET fraction $\left(\mathrm{ET}_{\mathrm{ALEXI}} / F_{\text {ref }}\right)$, where $\mathrm{ET}_{\mathrm{ALEXI}}$ is the actual $\mathrm{ET}$ from the ALEXI model and $F_{\text {ref }}$ is a reference ET flux based on the Penman-Monteith formulation as codified in the Food and Agriculture Organization (FAO) FAO-56 standard (Allen et al. 1998). An ET fraction is used when computing the ESI to minimize the impact of non-moisture-related drivers on ET, such as seasonal changes in radiation. Because the ALEXI model uses the morning rise in LST to compute ET, it can only be applied to satellite pixels that remain clear during the morning hours used to compute the change in LST. Most cloudy pixels are successfully removed using a cloud mask algorithm; however, optically thin clouds are occasionally missed, which can lead to spurious ET retrievals. A temporal smoothing algorithm is used to reduce random noise in daily ET retrievals caused by incomplete cloud screening (Anderson et al. 2013). Daily ET values, on average, are computed at least once per week for $75 \%$ of the CONUS domain, with $95 \%$ of the grid points updated at least once every 20 days (Anderson et al. 2007b). To achieve more complete domain coverage, daily clear-sky ET estimates can be composited over longer multiweek periods:

$$
\langle v(w, y)\rangle=\frac{1}{n_{c}} \sum_{n=1}^{n_{c}} v(n, y),
$$


where $\langle v(w, y)\rangle$ is the composite value for week $w$ and year $y$ at a given grid point, $v(n, y)$ is the ET fraction on day $n$, and $n_{c}$ is the number of clear days during the composite time interval. Though temporal compositing of the clear-sky retrievals will reduce the ESI response time to changing surface moisture conditions, this reduction should be minor because droughts are usually associated with predominantly clear skies, thereby promoting frequent ET updates.

ESI anomalies, expressed as pseudo $z$ scores normalized to a mean of 0 and a standard deviation of 1 , are routinely computed each week for 2-, 4-, and 8-week composite periods during the nominal growing season (April-October) across the CONUS (http://hrsl.arsusda. gov/drought). The mean ET fraction and standard deviation is computed at each grid point for each composite period using data from the 2000-12 ALEXI period of record. Standardized anomalies are subsequently computed as

$$
\operatorname{ESI}(w, y)=\frac{\langle v(w, y)\rangle-\frac{1}{n_{y}} \sum_{y=1}^{n_{y}}\langle v(w, y)\rangle}{\sigma(w)},
$$

where the second term in the numerator represents the mean conditions averaged over all years and the denominator is the standard deviation. Negative values depict reduced soil moisture availability and poorer-thanaverage vegetation health. ESI values less than -1 represent dry conditions exceeding $1 \sigma$, which should occur $\sim 16 \%$ of the time, assuming a normal distribution.

Recent work by Otkin et al. (2013) and Anderson et al. (2013) has shown that temporal changes in multiweek ESI composites often convey useful information about the rate at which moisture stress is increasing and can provide early warning of drought initiation and intensification. To aid identification of regions experiencing rapid changes in ET, ESI change anomalies, denoted $\Delta \mathrm{ESI}$, are computed by differencing composites of ET fraction over 1-, 2-, 3-, and 4-week periods for each of the ESI composite periods $(2,4$, and 8 weeks) and then computing standardized anomalies in the difference products:

$$
\begin{aligned}
\Delta \operatorname{ESI}\left(w_{1}, w_{2}, y\right) & \\
= & \frac{\left\langle v\left(w_{2}, y\right)-v\left(w_{1}, y\right)\right\rangle-\frac{1}{n_{y}} \sum_{y=1}^{n_{y}}\left\langle v\left(w_{2}, y\right)-v\left(w_{1}, y\right)\right\rangle}{\sigma\left(w_{1}, w_{2}\right)},
\end{aligned}
$$

where $w_{1}$ and $w_{2}$ are the two weeks used in the difference computation. The different compositing and differencing intervals create a set of $12 \Delta \mathrm{ESI}$ variables that can provide early warning of drought intensification across multiple time scales. Large negative $\Delta \mathrm{ESI}$ anomalies indicate that moisture stress is increasing rapidly relative to average conditions experienced during the 2000-12 ALEXI baseline period of record.

\section{c. Rapid change index}

Because anomalous weather patterns conducive to either drought development or drought recovery can persist for many weeks, large $\Delta$ ESI anomalies can also occur for an extended period of time as the ESI composites respond to sustained changes in moisture stress and vegetation health. Thus, it may be helpful to express the cumulative magnitude of the weekly $\Delta \mathrm{ESI}$ anomalies in the form of an RCI that encapsulates the anomalous rate of moisture stress change for the full duration of a rapid change event. As such, the RCI may provide additional information about the likelihood of future changes in drought severity that weekly $\Delta$ ESI anomalies alone may not be able to provide. Because the response time to changing moisture stress varies among the 12 $\Delta$ ESI variables, with the shorter compositing and differencing intervals typically exhibiting faster response times (Otkin et al. 2013), individual RCI values were computed for each $\Delta E S I$ variable. Some combination of the resultant set of 12 RCI values could also be constructed, but that is beyond the scope of this study. As described in the remainder of this section, the RCI is designed so that it can be used to identify areas experiencing unusually rapid increases or decreases in moisture stress; however, the primary focus of this study will be to examine the utility of the RCI as a drought early warning tool.

At a date preceding the beginning of each growing season, nominally defined as 1 March, each of the 12 RCI variables is set to 0 . The RCI only increases (decreases) in subsequent weeks if the corresponding $\triangle \mathrm{ESI}$ value is above (below) a certain threshold. To highlight areas of unusually large moisture stress changes, this threshold was set to \pm 0.75 , which occurs $\sim 22 \%$ of the time in a normal distribution and is similar to that used by prior studies to define the occurrence of drought in soil moisture percentiles (e.g., Mo 2008). For a given week, the $\mathrm{RCI}$ is computed as

$$
\begin{aligned}
& \mathrm{RCI}=\mathrm{RCI}_{\text {prev }}-\sqrt{\mathrm{abs}(\Delta \mathrm{ESI})-0.75} \\
& \text { if } \quad \Delta \mathrm{ESI}<-0.75 \text { and } \\
& \mathrm{RCI}=\mathrm{RCI}_{\text {prev }}+\sqrt{\Delta \mathrm{ESI}-0.75} \\
& \text { if } \Delta \mathrm{ESI}>0.75,
\end{aligned}
$$

where $\mathrm{RCI}_{\text {prev }}$ is the RCI value from the previous week. Thus, negative RCI values correspond to rapidly 
increasing moisture stress, whereas positive values indicate improving conditions. The RCI resets to zero if the sign of the $\Delta$ ESI anomaly for the current week is opposite that of the prior week, but remains negative (positive) if the $\Delta$ ESI anomaly has the same sign as the prior week but is above (below) the chosen threshold. The RCI is not reset to zero in these situations to account for short-term breaks in the occurrence of large $\Delta$ ESI values of the same sign, thereby preventing the erroneous separation of a discrete, long-duration drying or moistening event into several shorter events. Sensitivity tests showed that using a square root of the difference between the $\Delta \mathrm{ESI}$ and threshold values provided better agreement between the $\mathrm{RCI}$ and changes in drought severity as depicted by the USDM. Herein, the 12 RCI variables are denoted as RCI_(change interval)_( $\Delta$ ESI composite length), such that the RCI_CH1_02WK variable is computed using 1week changes in the 2 -week $\Delta$ ESI composites. The 12 RCI variables were computed for each week during the 2000-12 ALEXI period of record.

\section{d. U.S. Drought Monitor}

The USDM is created each week through expert synthesis of pertinent drought information from multiple data streams, including rainfall and soil moisture percentiles; surface streamflow departures; existing drought diagnostic metrics; crop conditions; and local observations, data, and impact reports from observers across the country (Svoboda et al. 2002). The USDM classifies drought severity into four categories ranging from moderate to exceptional drought. There is also a fifth category that reflects abnormally dry conditions. For this study, USDM analyses provided by the National Drought Mitigation Center in shape area format were interpolated to the 10-km ALEXI grid by assigning numerical values to each drought category, with no drought $=-1$, abnormally dry $(\mathrm{D} 0)=0$, moderate drought $(\mathrm{D} 1)=1$, severe drought $(D 2)=2$, extreme drought $(\mathrm{D} 3)=3$, and exceptional drought $(\mathrm{D} 4)=4$. Though the USDM should not be considered an absolute measure of drought severity because it conveys information about drought at multiple time scales and for a variety of impacts (agricultural, hydrological, and socioeconomic), comparisons with the USDM are still useful for evaluating the drought early warning capability of the ESI.

\section{Results}

\section{a. Drought case studies}

To illustrate the spatial and temporal congruence between the RCI and USDM datasets, a detailed evaluation of two rapid onset drought events that occurred across the central United States is presented in this section. Figure 1 shows the evolution of the 2-week accumulated rainfall, 2-week ESI composite anomalies (ESI_2WK), RCI_CH1_2WK, and USDM analyses at 2-week intervals from 8 July to 16 September 2003. For brevity, only the RCI_CH1_2WK data are shown as this index typically responds fastest to changing soil moisture conditions (refer to section 3c). Daily rainfall from the Climate Prediction Center's $0.25^{\circ}$-resolution precipitation analysis (Higgins et al. 2000) was summed to create 2-week rainfall totals.

At the beginning of July, the drought situation across the central United States was rather complex, with several pockets of abnormal dryness evident in the ESI_2WK and USDM analyses. Large positive RCI_CH1_2WK values had developed across the western Corn Belt in response to widespread beneficial rainfall during previous weeks that had greatly improved soil moisture conditions. Further to the south, however, persistent low rainfall led to rapid increases in moisture stress across a large portion of the central and southern plains, as indicated by the development of large negative ESI_2WK and RCI_CH1_2WK values by 22 July. The USDM depiction across this region rapidly transitioned from having only scattered areas of abnormal dryness to widespread moderate-to-severe drought conditions several weeks later, with some areas experiencing up to a three-category increase in drought severity over a 4-week period. By the middle of August, the period of rapid intensification had ended across the southern half of the region as indicated by the lack of negative RCI_CH1_2WK values. Farther to the north, however, very low rainfall and unusually warm temperatures (not shown) during August provided suitable conditions for rapid drought development from Nebraska and South Dakota eastward to Wisconsin, with large negative ESI_2WK anomalies encompassing the region by 2 September. The initial appearance of large negative RCI_CH1_2WK values on 5 August indicates that conditions were deteriorating rapidly and presaged the introduction of moderate-to-severe drought in the USDM by several weeks. Finally, a band of heavy rainfall provided drought relief from Kansas eastward to the Ohio River Valley by the end of August. Though late in the growing season, the vegetation responded well to the improved moisture conditions, with a large band of positive RCI_CH1_2WK values on 16 September collocated with the region of heavy precipitation. This demonstrates the potential utility of the RCI as an indicator of both rapid increases and rapid decreases in moisture stress.

The second case study shown in Fig. 2 depicts the evolution of the severe flash drought event that impacted the central United States during the summer of 2012. Record warm temperatures during the spring combined 

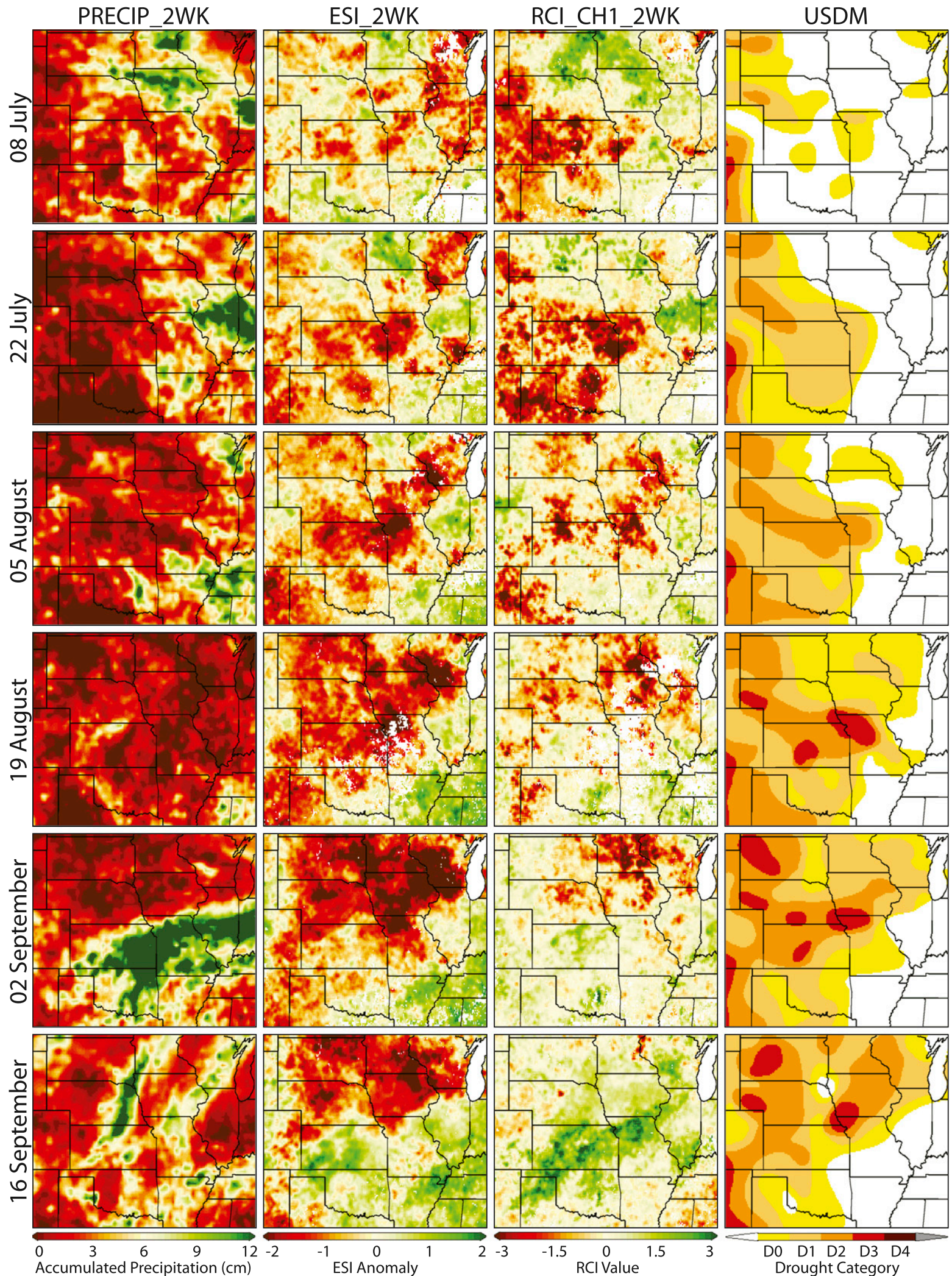

FIG. 1. Temporal evolution of 2-week accumulated precipitation, ESI_2WK composites, RCI_CH1_2WK, and USDM drought depiction from 8 Jul to 16 Sep 2003. 

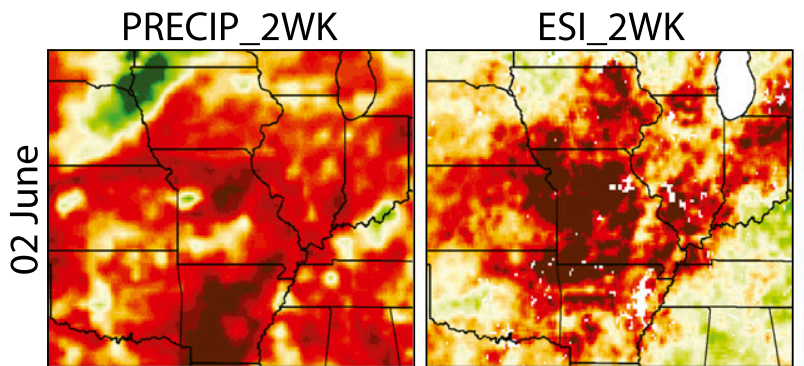

$\mathrm{RCl} \mathrm{CH} 12 \mathrm{WK}$
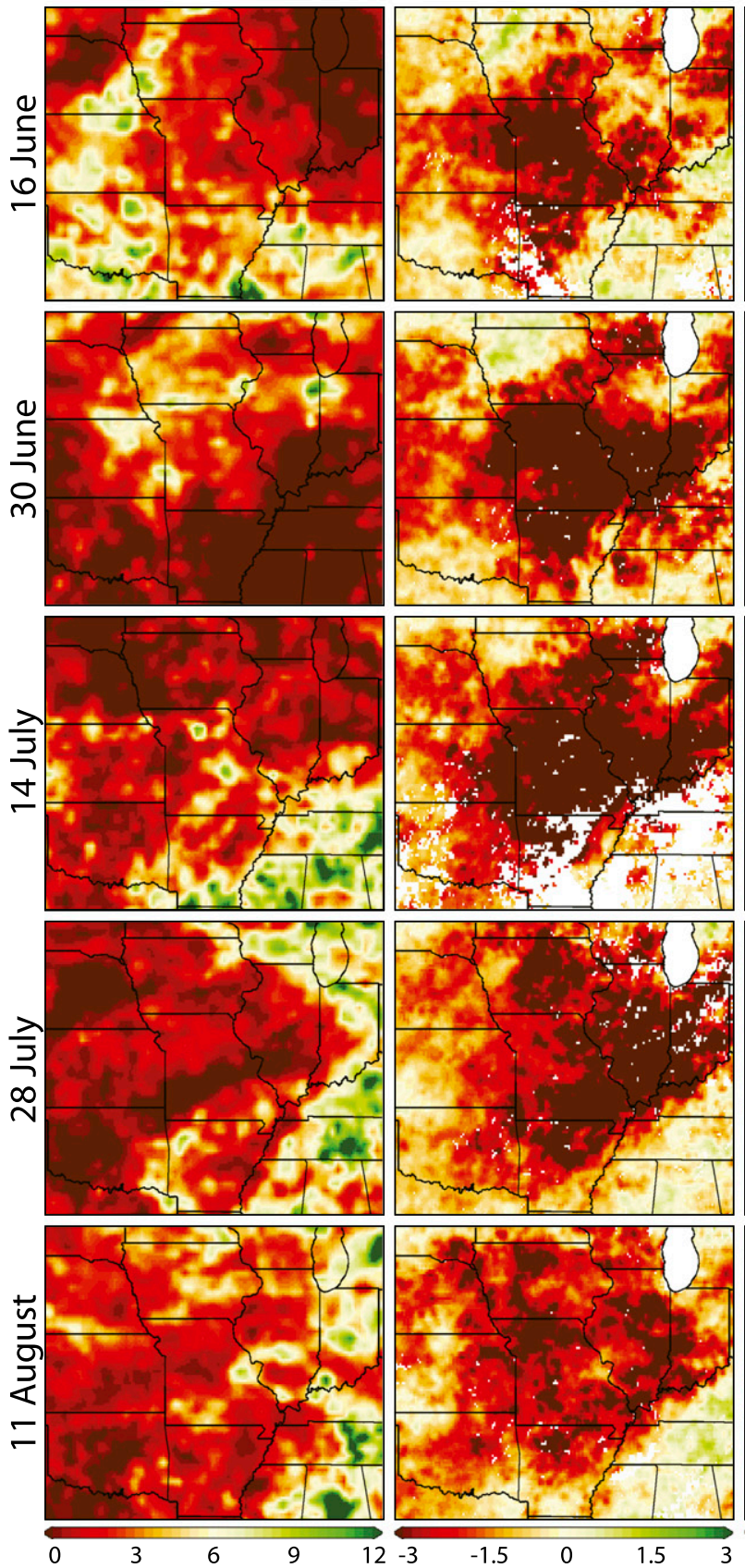

Accumulated Precipitation $(\mathrm{cm})$
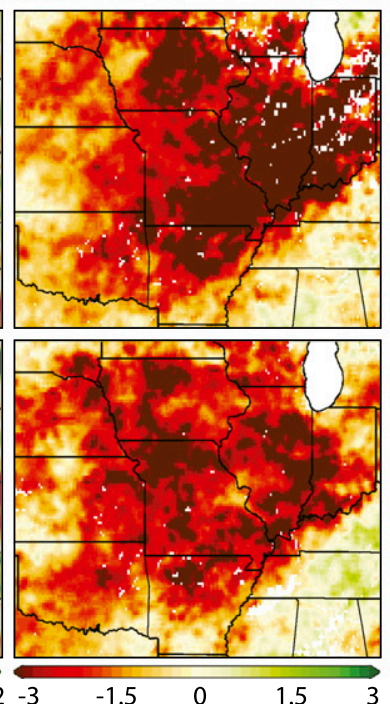

ESI Anomaly
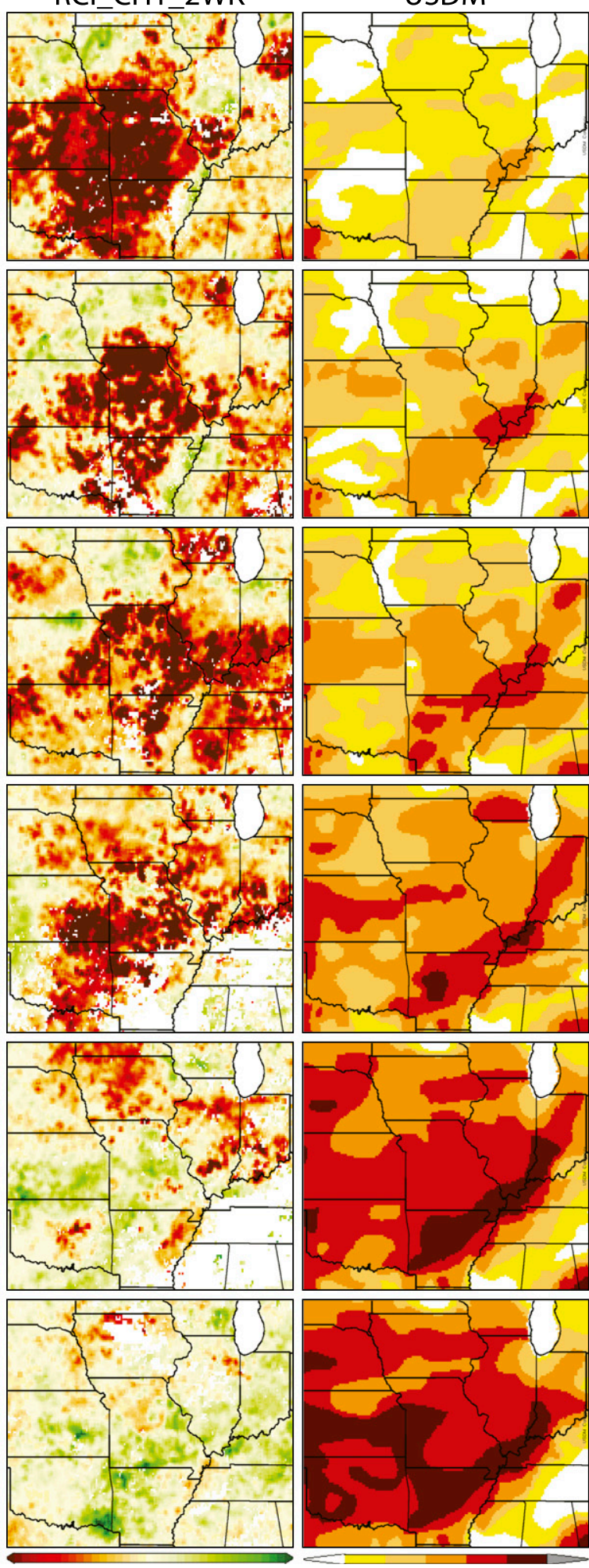

D0 $\quad$ D1 $\quad$ D2 D3 D4

Drought Category

FIG. 2. Temporal evolution of 2-week accumulated precipitation, ESI_2WK composites, RCI_CH1_2WK, and USDM drought depiction from 2 Jun to 11 Aug 2012. 
1 Category USDM Increase
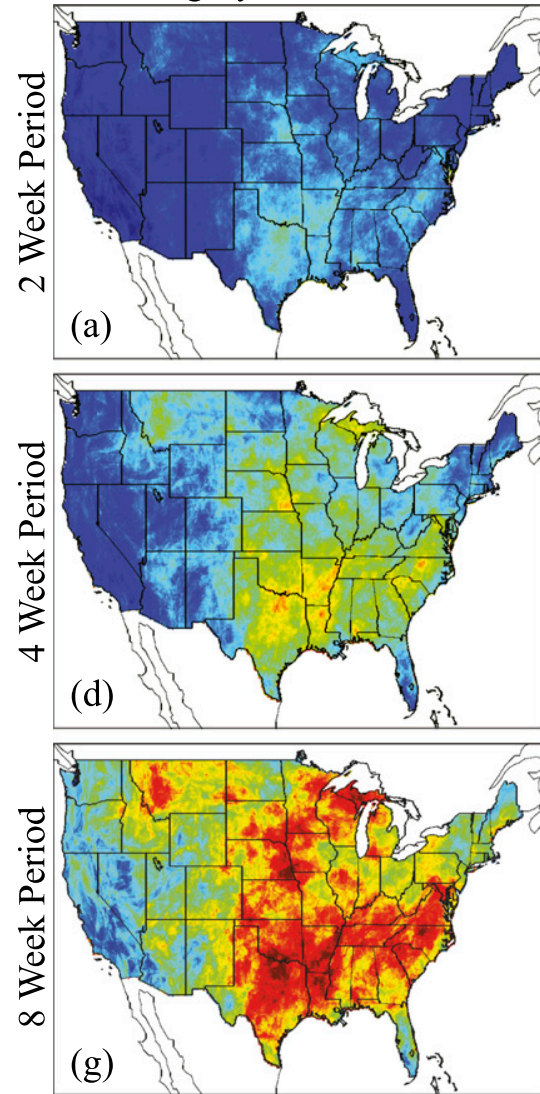

2 Category USDM Increase
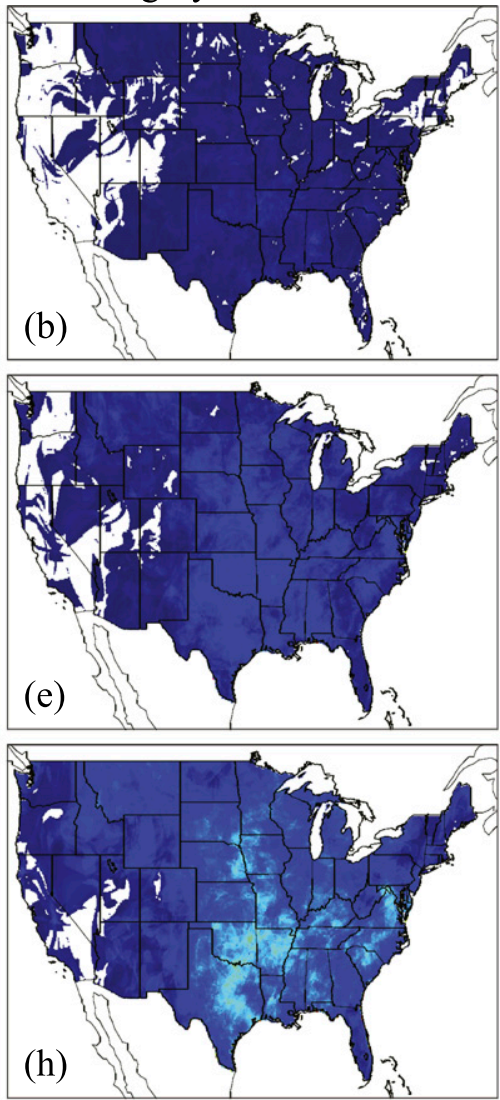

3 Category USDM Increase
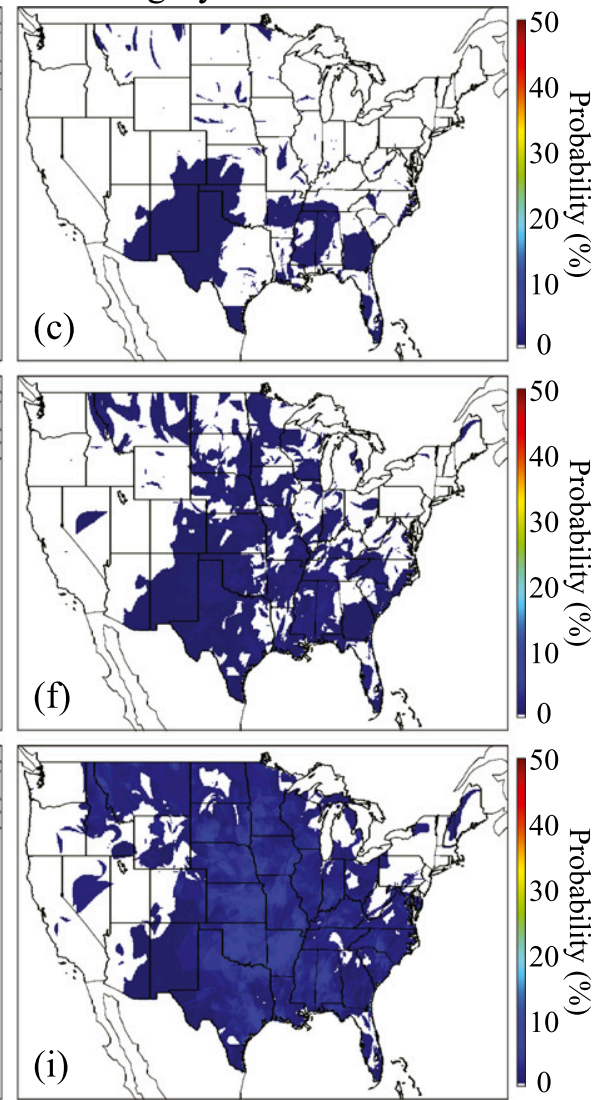

FIG. 3. Probability that the USDM depiction will increase by at least (a) one, (b) two, or (c) three categories during a 2-week period. (d)-(f) As in (a)-(c), but for increases occurring during a 4-week period. (g)-(i) As in (a)-(c), but for increases occurring during an 8-week period. All probabilities are computed using weekly data from 15 Apr to 30 Sep during the 2000-12 ALEXI period of record.

with normal to slightly below normal rainfall allowed abnormally dry conditions to prevail across much of the region at the beginning of summer. Though not evident in the USDM analysis on 2 June, the large negative ESI_2WK and RCI_CH1_2WK values across the southcentral United States indicate that moisture stress had already substantially increased by this time. Continued dryness and extreme heat during June and July led to unprecedented moisture stress (within the 2000-12 ALEXI period of record) characterized by extensive areas with ESI_2WK anomalies more than three standard deviations below the climatological mean. The impressive scope of the unusually rapid decrease in the ESI_2WK anomalies is clearly depicted by the extensive region of large negative RCI_CH1_2WK values on 2 June that then spread to surrounding areas during subsequent weeks. In many locations, the initial appearance of negative RCI_CH1_2WK values preceded the introduction of severe-to-exceptional drought in the USDM by more than 4 weeks. For instance, the USDM depiction over southwestern Missouri and eastern Kansas transitioned from abnormally dry conditions to exceptional drought (D4) during the 2-month period following the largest RCI_CH1_2WK values on 2 June. Other places, such as southern Wisconsin and western Indiana, also experienced rapid increases in USDM-depicted drought severity after the initial appearance of large RCI_CH1_2WK values. These case study results indicate that temporal changes in the ESI composites can provide critical drought early warning information that could alert stakeholders of an enhanced risk for rapid drought development.

\section{b. Drought intensification probabilities}

To more thoroughly investigate the drought early warning capability of the RCI variables during the nominal growing season (from 15 April to 30 September), the probability of future deterioration in the USDM severity assessment was evaluated as a function of RCI magnitude for each grid point in the ALEXI domain. For this 
1 Category USDM Increase
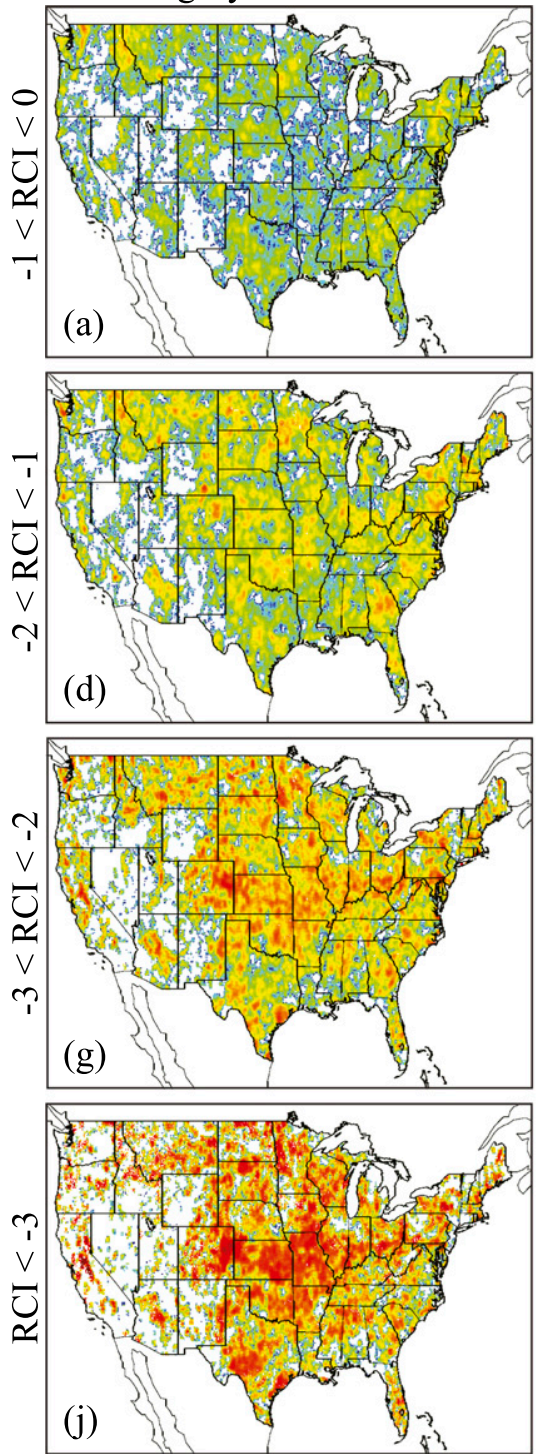

2 Category USDM Increase
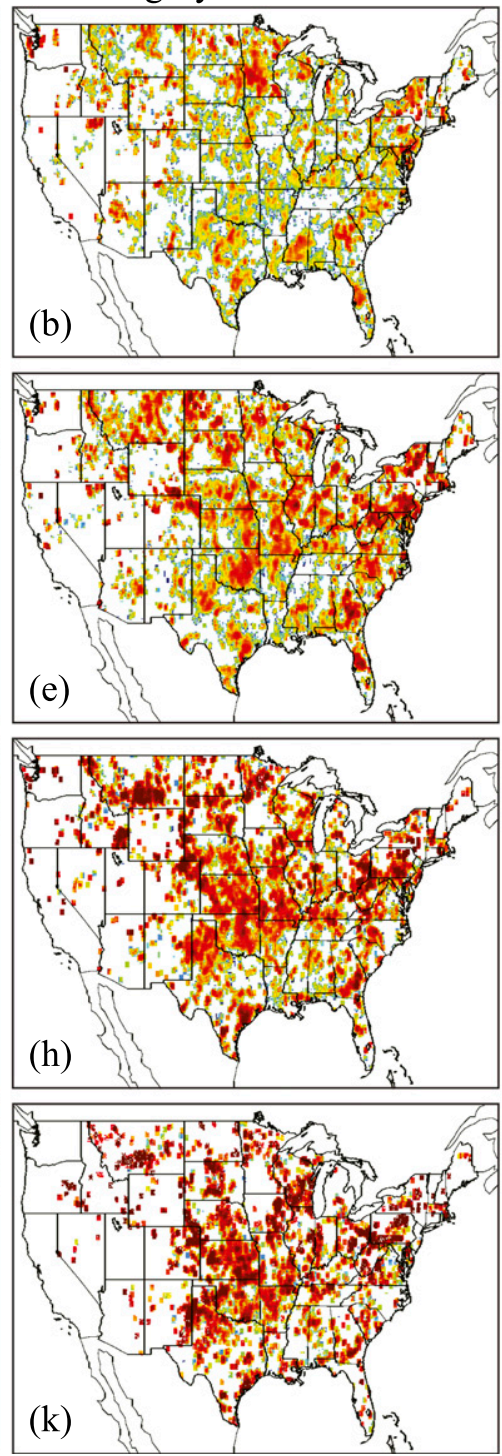

3 Category USDM Increase
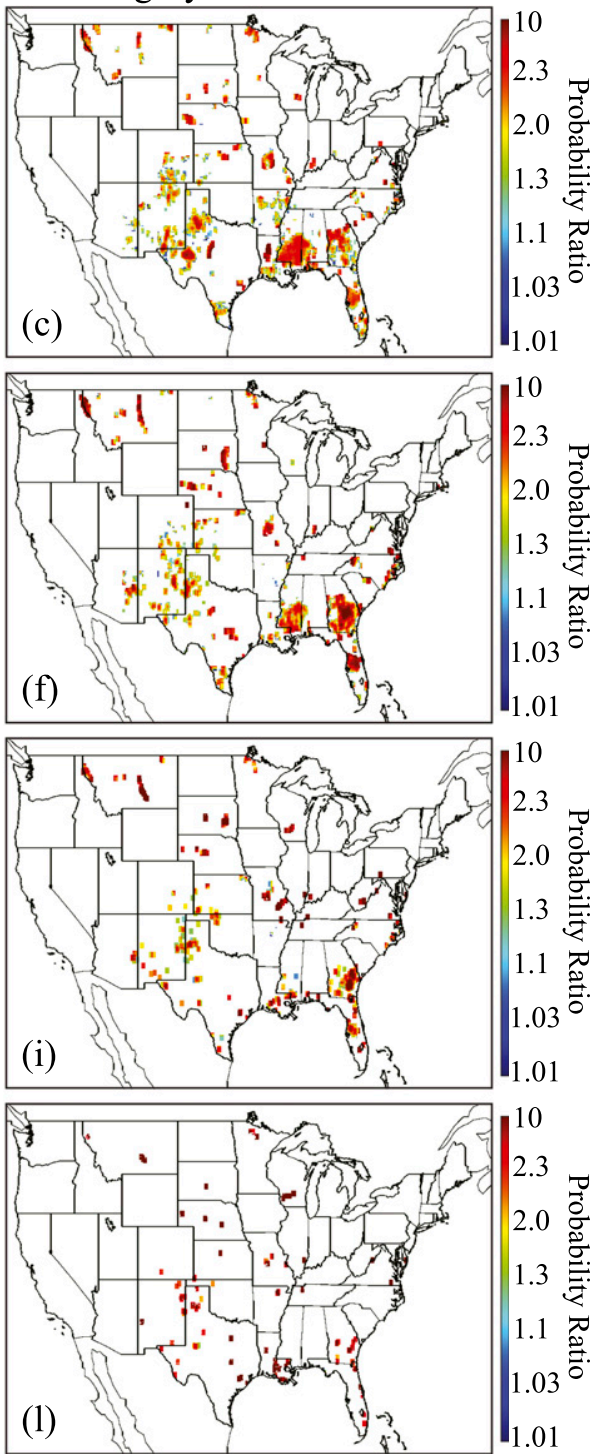

FIG. 4. Ratio of observed to climatological probabilities that the USDM depiction will increase by at least (a) one, (b) two, or (c) three categories during a 2-week period if $-1<\mathrm{RCI}<0$. (d)-(f) As in (a)-(c), but for probabilities corresponding to $-2<\mathrm{RCI}<-1$. (g)-(i) As in (a)-(c), but for probabilities corresponding to $-3<\mathrm{RCI}<-2$. (j)-(1) As in (a)-(c), but for probabilities corresponding to RCI $<-3$. Probabilities are computed for the RCI_CH1_2WK variable using weekly data from 15 Apr to 30 Sep during the 2000-12 ALEXI period of record.

analysis, negative RCI values during the 2000-12 ALEXI period of record were separated into four bins, including $\mathrm{RCI}<-3,-3<\mathrm{RCI}<-2,-2<\mathrm{RCI}<-1$, and $-1<$ $\mathrm{RCI}<0$. To eliminate the possibility of including more than 1 week from a given rapid drying event within each $\mathrm{RCI}$ bin, the probabilities were computed using data only from the first week that the RCI is in each bin. For each week that satisfies this constraint, the maximum increase in drought severity during subsequent 2-, 4-, and 8-week periods was determined, and then the full sample obtained for each bin was used to compute the probability that the USDM will increase by at least one, two, or three categories during each time period. These probabilities were computed separately for each RCI variable. With this information, the likelihood of future drought intensification can be assessed for different forecast periods based on the value of the RCI in any given week.

Because some areas of the United States are more susceptible to drought development, it is important to compare the RCI-based drought intensification probabilities to those derived from local climatology. Figure 3 shows the baseline probability that the USDM severity 
1 Category USDM Increase
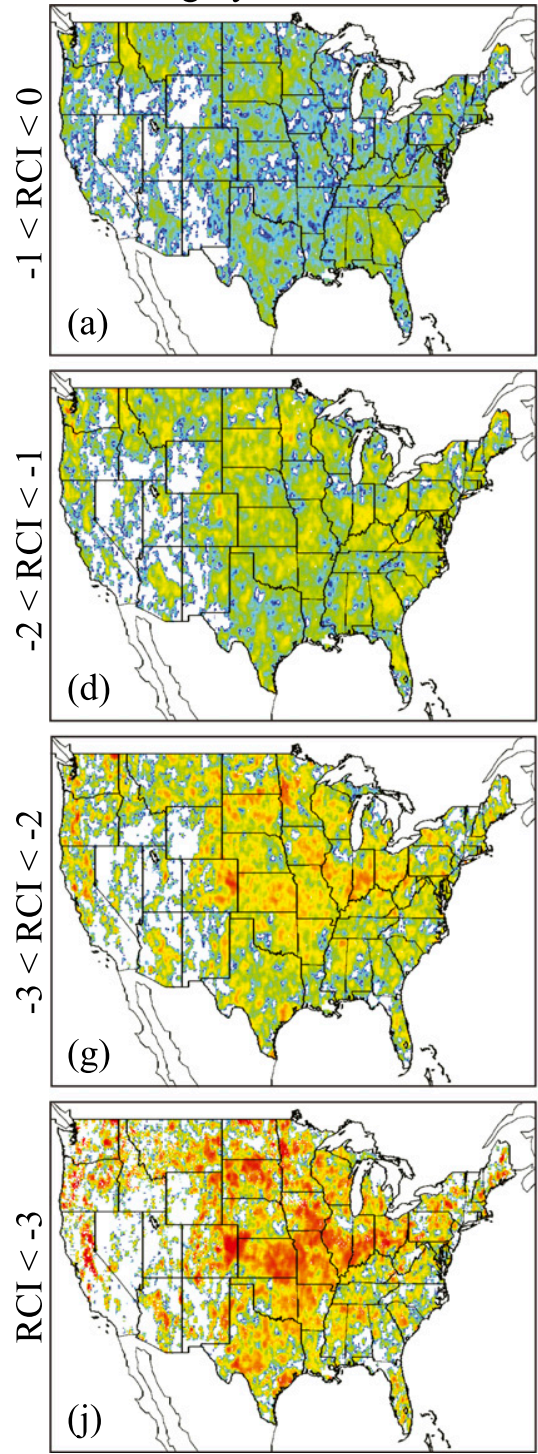

2 Category USDM Increase
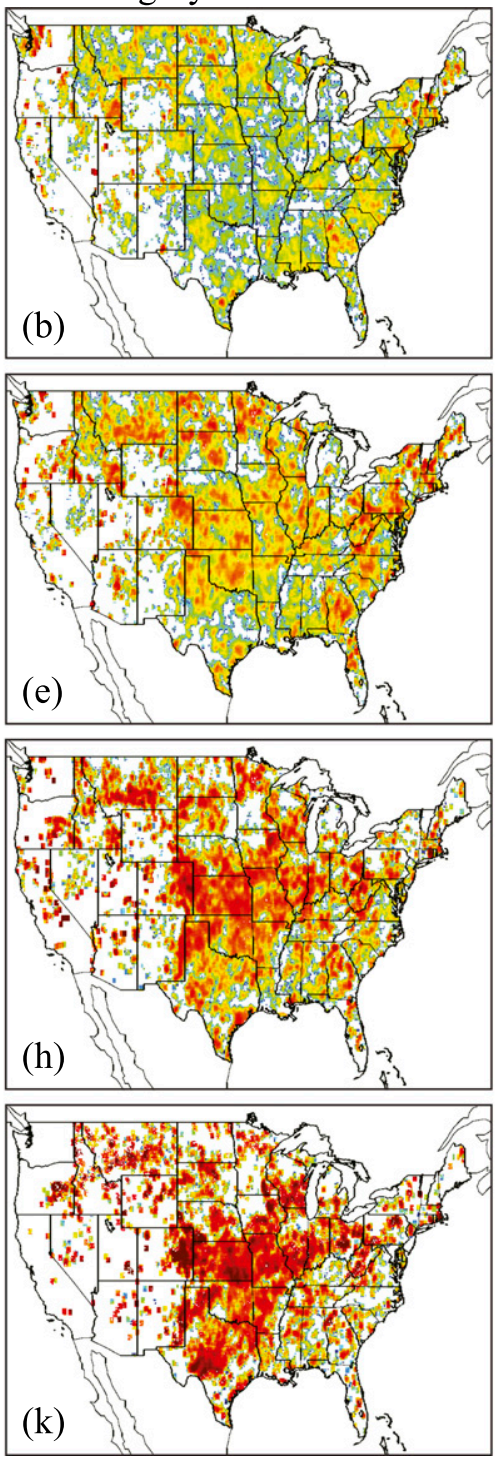

3 Category USDM Increase
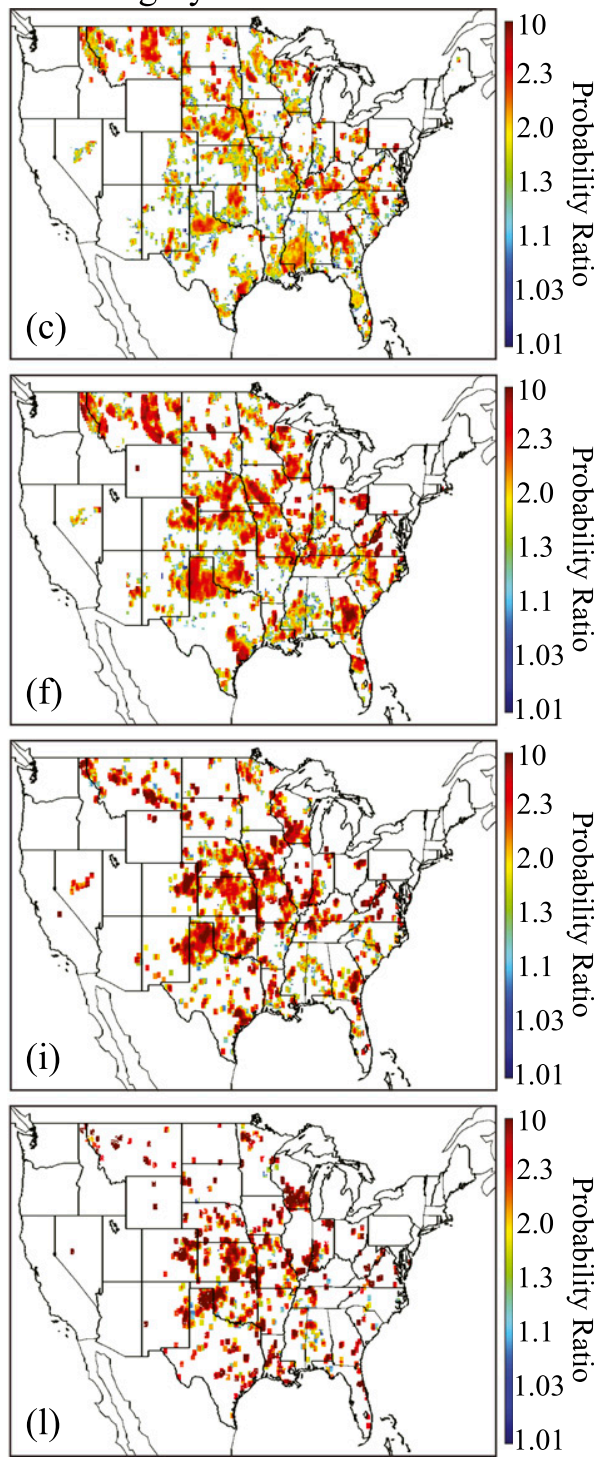

FIG. 5. As in Fig. 4, but for a 4-week period.

depiction will increase by at least one, two, or three categories during any 2-, 4-, or 8-week period from 15 April to 30 September, based on USDM data from the 2000-12 period. Given the limited length of the dataset, it is possible that these probabilities will differ slightly if a longer-term climatology were used; however, to be consistent with the ESI dataset, it is necessary to limit the evaluation to the same time period. As expected, the likelihood of drought intensification increases for longer time periods and decreases for larger USDM severity changes. The highest probabilities encompass much of the central and southeastern United States, with lower probabilities across the western United States and from eastern Iowa northeastward to New England. Across the central United States, the north-south band of higher probabilities lies within a sharp east-west gradient in precipitation and vegetation cover that is characterized by strong interannual and seasonal variability in ET and soil moisture availability (Guo and Dirmeyer 2013). Lower probabilities over the western United States reflect the propensity for the USDM to depict slowly evolving, hydrological droughts related primarily to changes in seasonal snowpack conditions, whereas over the northeastern United States, drought is less common because of reduced water demand associated with cooler temperatures and generally adequate rainfall.

In the remainder of this section, drought intensification probabilities computed using data from the 
1 Category USDM Increase
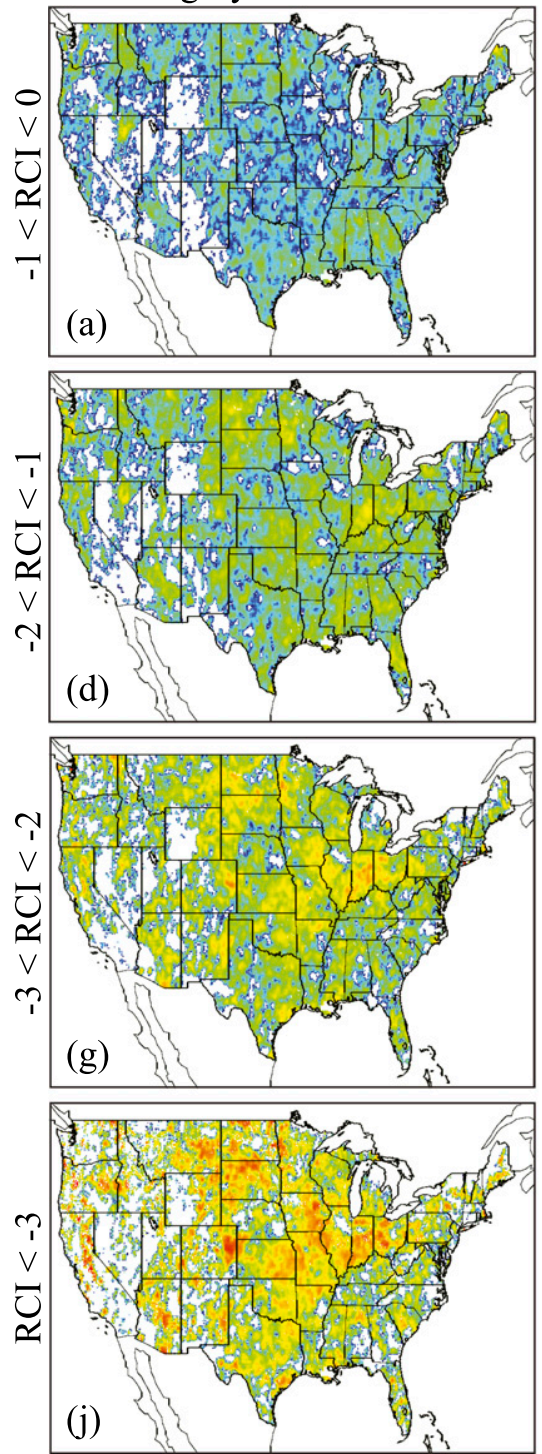

2 Category USDM Increase
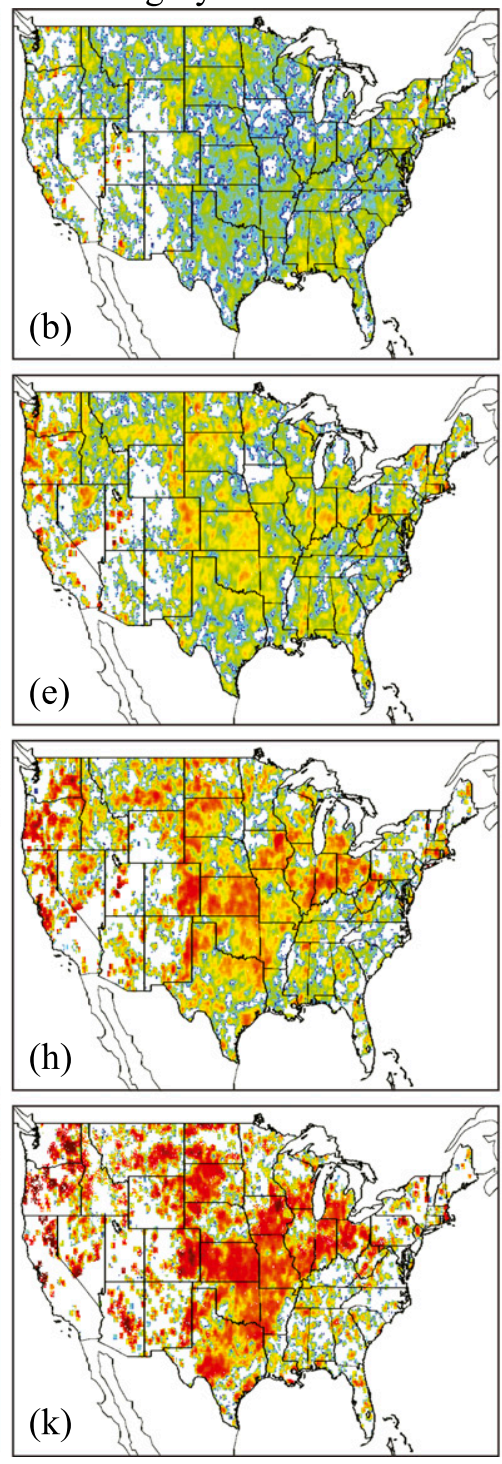

3 Category USDM Increase
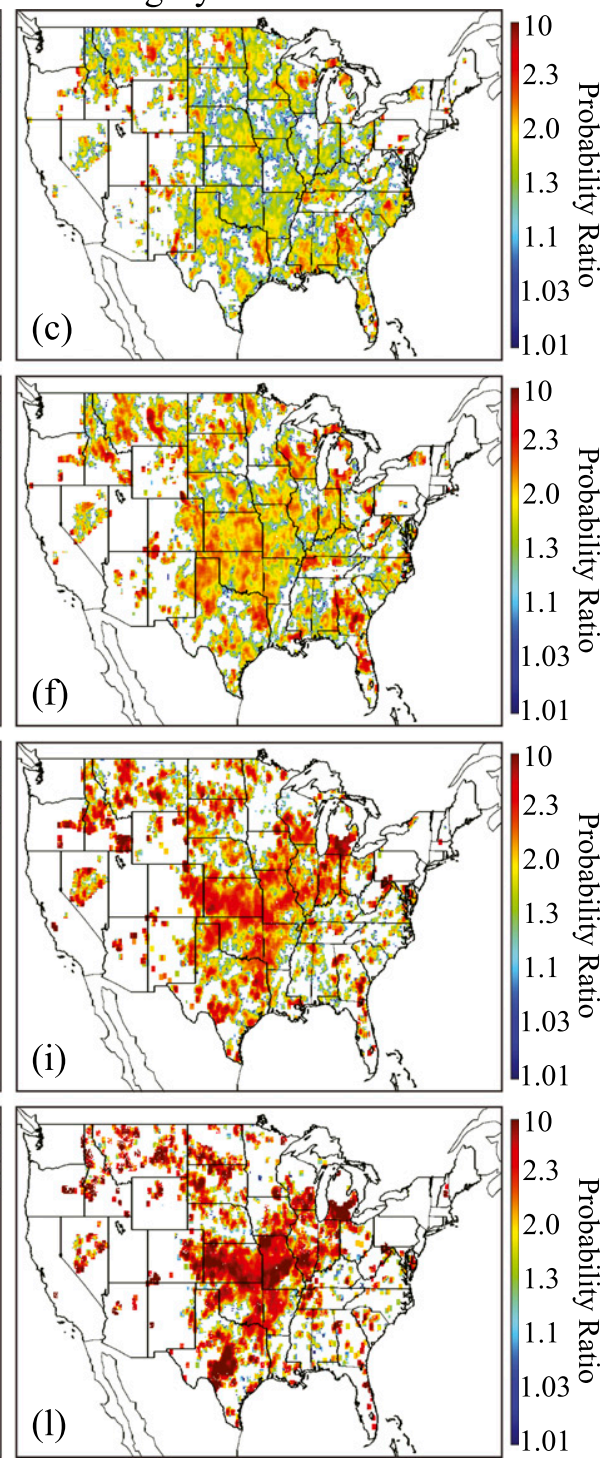

FIG. 6. As in Fig. 4, but for an 8-week period.

RCI_CH1_2WK variable are compared to the baseline probabilities shown in Fig. 3 to assess its drought early warning capabilities. To more easily account for regional variations in drought intensification, Fig. 4 shows the ratio between the RCI-derived and climatological probabilities for USDM changes occurring over a 2-week period computed for each RCI bin. With this depiction, a value of 2 shows that a given drought intensity change occurs twice as often when the RCI is within a specific bin, indicating a much higher risk for deteriorating conditions than climatology would suggest. White areas denote regions where either no additional skill is gained with the RCI data or there are simply no cases with the specified USDM changes (e.g., refer to white areas in Fig. 3).
Overall, Fig. 4 demonstrates that for these short forecast lead times, much higher probabilities of drought intensification are indicated across most of the country when the $\mathrm{RCI}<0$. The probability ratios increase substantially for decreasing RCI values and for increasing USDM intensity changes, with many areas characterized by probability ratios $>3$ for the two-category changes in the USDM. The probability ratios for longer 4- and 8 -week periods shown in Figs. 5 and 6 remain high but are lower than those obtained for 2-week periods because the baseline drought intensification probabilities are higher (refer to Fig. 3). If this is taken into account, the RCI-derived probabilities are actually quite large across much of the central and eastern United States, with 


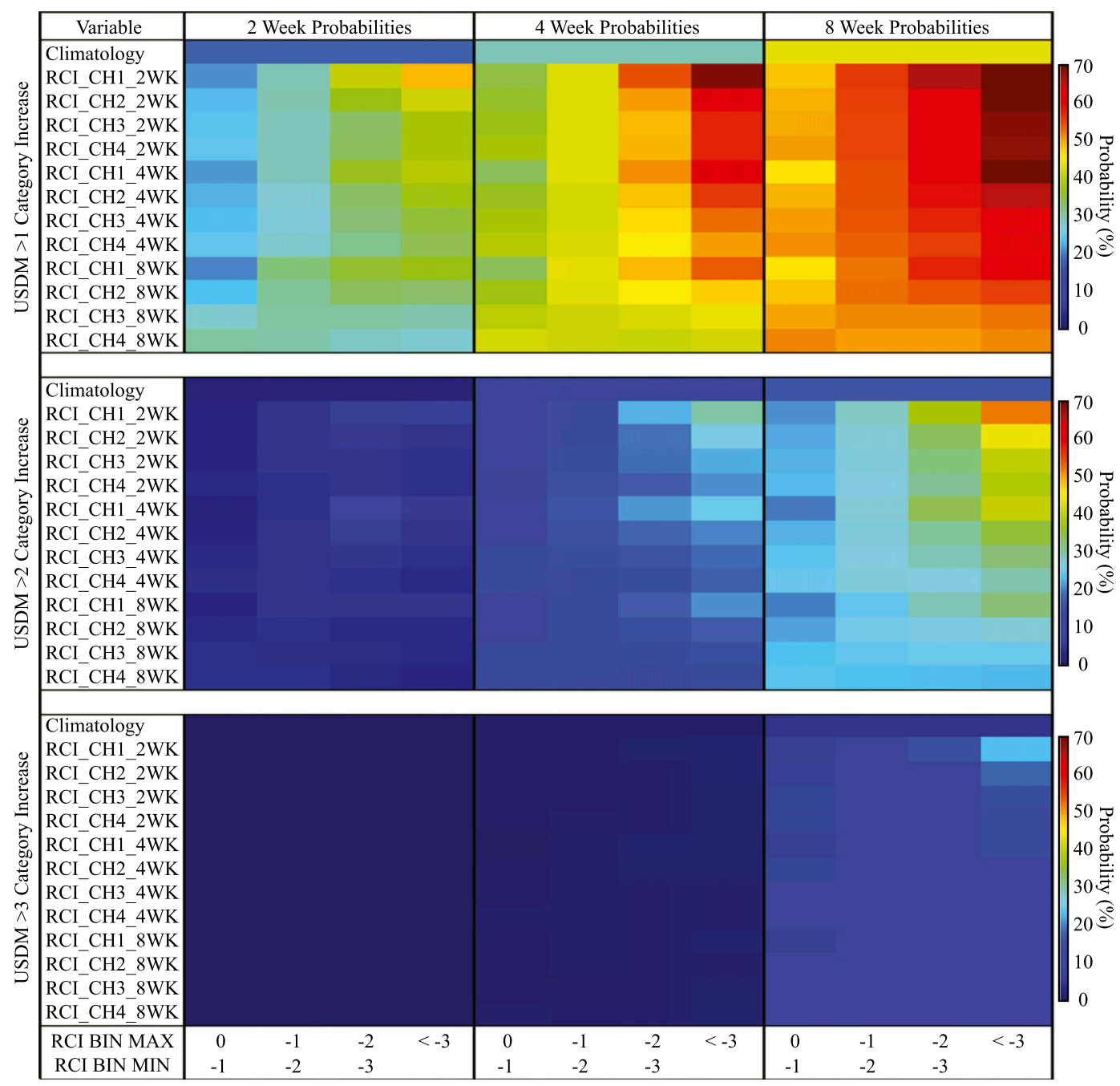

FIG. 7. Probability of at least a (top) one-, (middle) two-, or (bottom) three-category increase in the USDM severity during (left) 2-, (middle) 4-, and (right) 8-week periods, averaged over all grid points in eastern Oklahoma and western Arkansas. Probabilities are computed for each of the 12 RCI variables, with the climatological probability also indicated. Within each set of columns, the probabilities are computed for $-1<\mathrm{RCI}<0,-2<\mathrm{RCI}<-1$, $-3<\mathrm{RCI}<-2$, and RCI $<-3$.

probabilities often in excess of $50 \%$ for the larger $\mathrm{RCI}$ values. The drought early warning signal may be weaker over parts of the western United States because of the tendency for more persistent droughts and a greater emphasis on winter precipitation in the USDM depiction that reduces the relevance of rapid changes in ET during summer. Furthermore, because the ET signal is inherently low in the west, sensitivity in ESI to changing moisture conditions is lower than in the eastern United States (Anderson et al. 2013).

As was the case with the 2-week probabilities, large two- and three-category increases in USDM severity are much more likely to occur during 4- and 8-week periods when the RCI is negative, with the probability ratios becoming progressively larger as the RCI decreases. The higher ratios for the larger RCI values indicate that the accumulated time rate of moisture stress change encapsulated by the RCI can serve as a useful predictor of future increases in USDM-depicted drought severity and can provide effective early warning of an increased probability for rapid drought development. Comparison to Fig. 3 shows that the ratios are especially large over regions that are most susceptible to rapid drought intensification over the central and eastern United States.

\section{c. Regional drought probabilities}

In this section, the ability of each of the 12 RCI variables to provide early warning of an above-average risk 


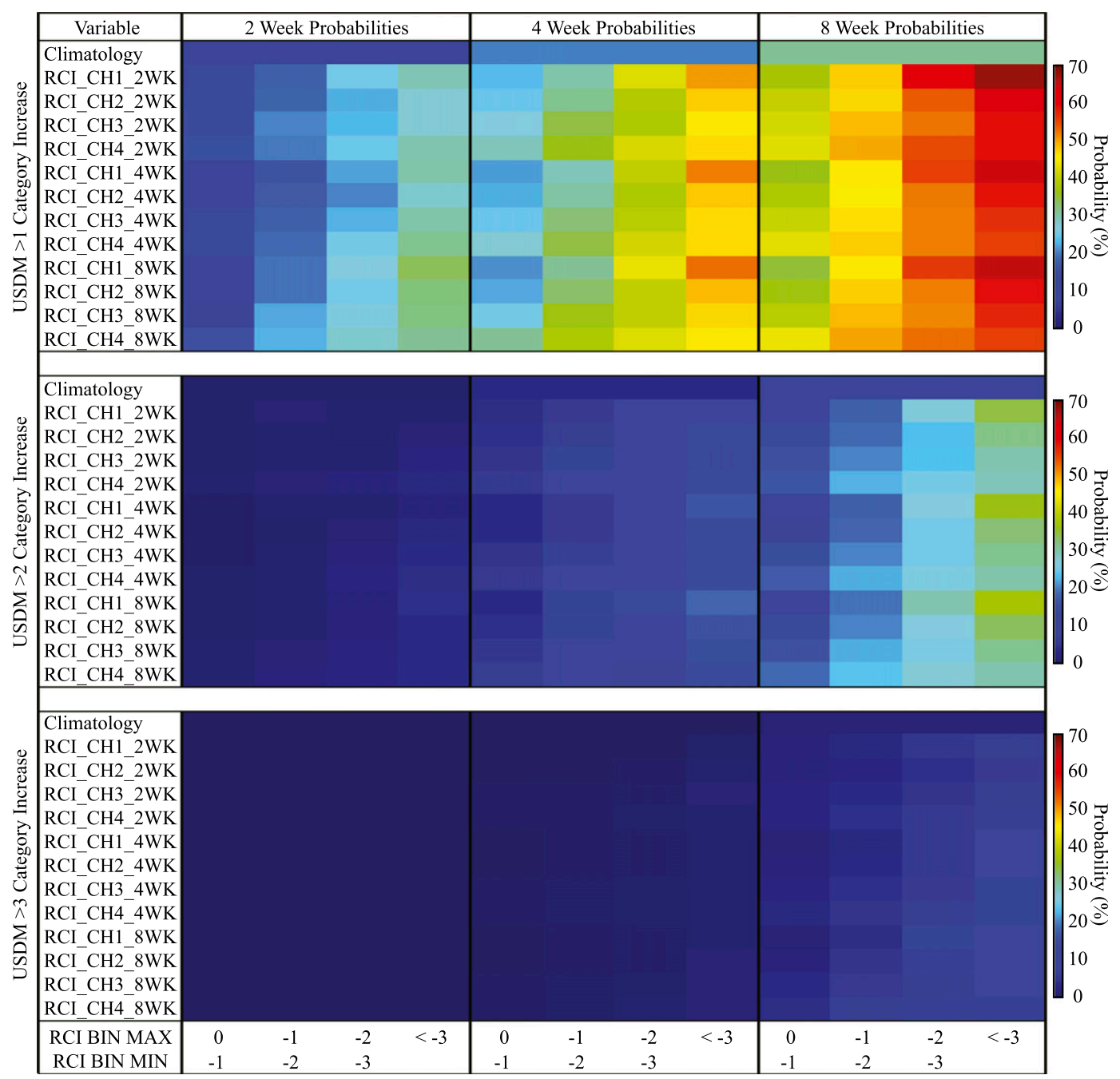

FIG. 8. As in Fig. 7, but for probabilities computed for eastern Indiana and western Ohio.

for drought development is assessed for three regions of the United States characterized by different land use patterns and vegetation types, ranging from a mixture of pasture and forest cover over eastern Oklahoma and western Arkansas to landscapes dominated by corn and soybeans in the Midwest. As described in the previous section, the probability of at least a one-, two-, or threecategory increase in the USDM depiction during 2-, 4-, and 8-week periods was computed for each RCI variable. Domain-average probabilities were then computed for each RCI bin using all grid points located within a given region. Because of the large sample of probabilities, a new visualization method was devised to more easily display the extensive information conveyed by these datasets. An example image displaying the probabilities for drought intensification over eastern Oklahoma and western Arkansas during 2000-12 is shown in Fig. 7. The probabilities are organized into three columns corresponding to 2-, 4-, and 8-week periods, respectively, with each column further divided to show the probabilities for each RCI bin. The 12 RCI variables, along with the baseline intensification probabilities, are then grouped into three sets of rows corresponding to one-, two-, and three-category increases in the USDM.

Inspection of Fig. 7 reveals that, compared to climatology, all of the RCI variables indicate a higher probability of drought intensification for all time and drought intensity change categories within this region. Consistent with the results shown in Figs. 4-6 for the RCI_CH1_2WK variable, the likelihood of drought intensification for the other RCI variables generally increases as they become more negative. The probabilities also tend to increase for longer time periods and for smaller USDM category changes. Though all of the RCI variables exhibit similar 


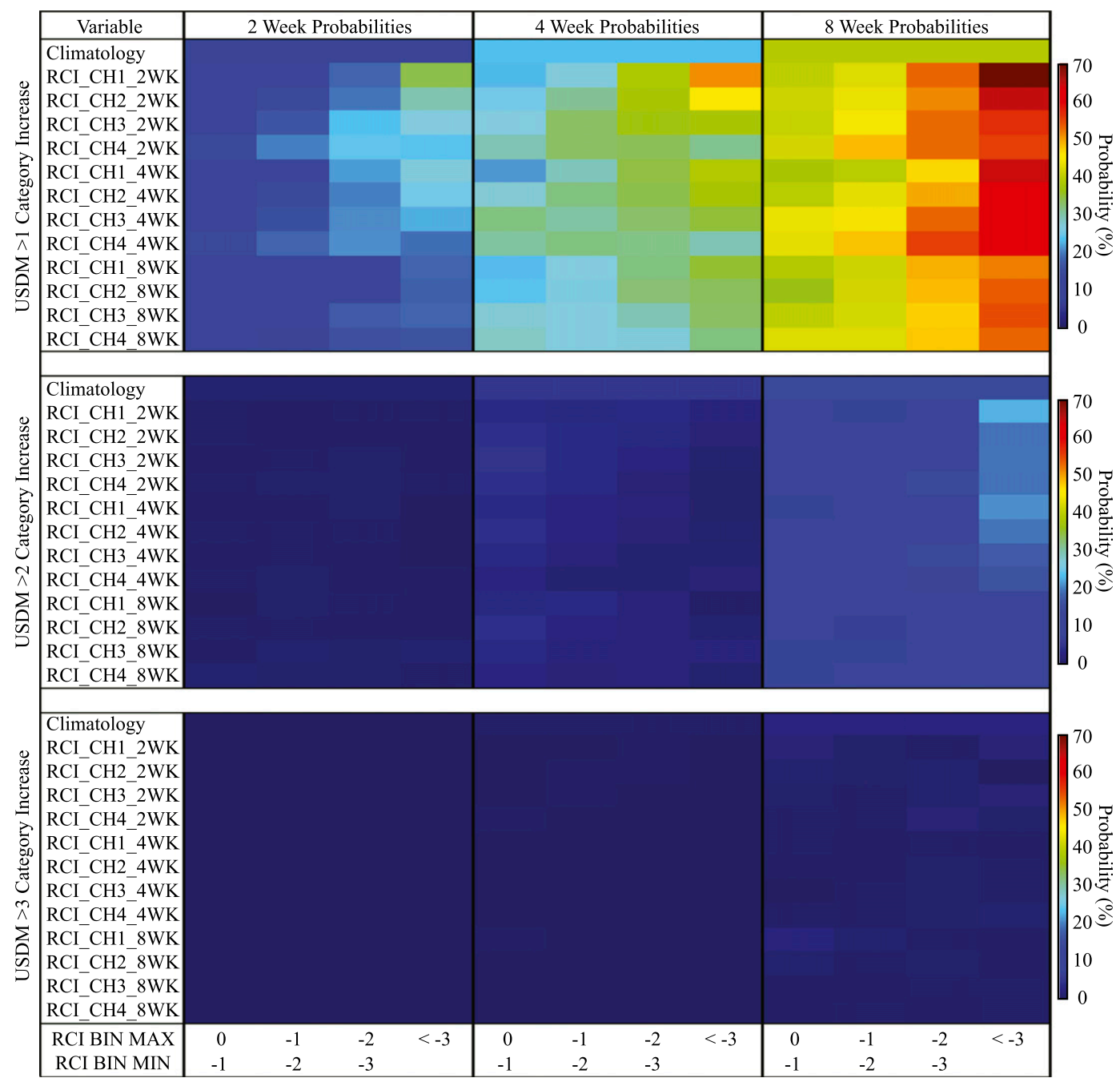

FIG. 9. As in Fig. 7, but for probabilities computed for northwestern Iowa.

qualitative behavior, large numerical differences are also apparent, with the probabilities generally increasing as the composite period length decreases from 8 weeks to 2 weeks. Within each composite period, the probabilities also tend to increase as the differencing interval decreases from 4 weeks to 1 week (e.g., from $\mathrm{CH} 4$ to $\mathrm{CH} 1$ ), though for the smallest RCI values, longer differencing intervals often exhibit higher probabilities. Because the USDM tends to be conservative when depicting rapid changes in drought severity, it is possible that shorter differencing intervals have lower probabilities for smaller RCI values because they are reflective of short-term changes in vegetation health that are simply not resolved by the USDM. This suggests that using different threshold values for each RCI variable may help refine these probabilities. For larger RCI values, the superior performance of the RCI variables computed using $\Delta \mathrm{ESI}$ data from shorter composite and time differencing intervals is consistent with the results shown by Otkin et al. (2013) and Anderson et al. (2013) for individual flash drought events and provides further evidence that rapid changes in ET over short time periods often serve as a precursor of drought development.

Figure 8 shows the drought intensification probabilities computed for the region encompassing the eastern half of Indiana and the western third of Ohio. In comparison to Fig. 7, lower probabilities occur over this region; however, all of the RCI variables still indicate an increased risk for drought development compared to climatology, especially for one-category USDM changes at all time scales and for two-category changes over 8-week periods. Overall, there is less sensitivity to the ESI composite period length as all RCI variables produce similar probabilities in each RCI bin. The lower 

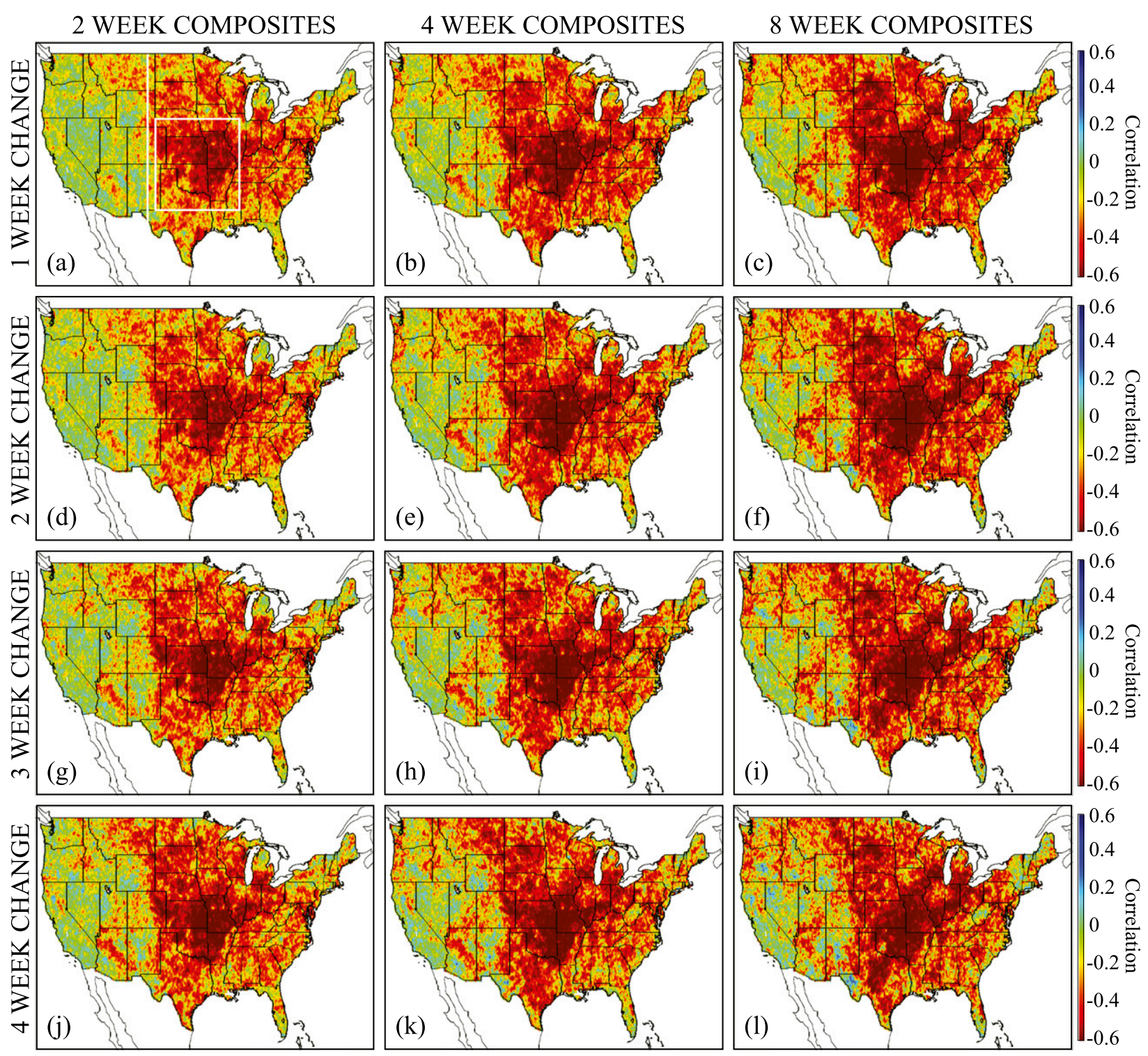

FIG. 10. Correlation between the max RCI value for each rapid change event and the max USDM category change from the beginning of the event until 2 weeks after its end for the (a) RCI_CH1_2WK, (b) RCI_CH1_4WK, (c) RCI_CH1_8WK, (d) RCI_CH2_2WK, (e) RCI_CH2_4WK, (f) RCI_CH2_8WK, (g) RCI_CH3_2WK, (h) RCI_CH3_4WK, (i) RCI_CH3_8WK, (j) RCI_CH4_2WK, (k) RCI_CH4_4WK, and (1) RCI_CH4_8WK variables. The vertical white line in (a) denotes the edge of the western and eastern U.S. regions used to compute the average correlations shown in Tables 1-3. The white box over the central United States denotes the core drought region.

probabilities over this region are not necessarily indicative of a higher false alarm rate in the RCI data. Instead, the RCI is predictive primarily because of the accumulated impact of moisture deficiencies that contribute to drought persistence and intensification. Thus, in regions with cooler temperatures and more frequent rainfall, such as the eastern Corn Belt, short-term periods of unusually rapid drying leading to the development of negative RCI values are often terminated by heavy rainfall that prevents further drought development. Combining the inferred rate of drying from the weekly RCI data with medium-range rainfall forecasts could potentially help to delineate those areas most susceptible to drought development.

Average drought intensification probabilities for the northwestern corner of Iowa are displayed in Fig. 9. As will be shown in the next section, this area lies within a region of lower correlations between the RCI and changes in the USDM depiction. The RCI probabilities in this region show no additional skill over the baseline 
TABLE 1. Correlation between the max value for each RCI variable and the max change in the USDM from $t_{\mathrm{beg}}$ to $t_{\mathrm{end}}+2 \mathrm{weeks}$ (where $t$ indicates time) for each rapid change event, averaged over the western and eastern United States and the central U.S. core area. The first column denotes the RCI change interval (1,2,3, or 4 weeks).

\begin{tabular}{|c|c|c|c|c|c|c|c|c|c|}
\hline & \multicolumn{3}{|c|}{ Western United States } & \multicolumn{3}{|c|}{ Eastern United States } & \multicolumn{3}{|c|}{ Central U.S. core area } \\
\hline & 2 weeks & 4 weeks & 8 weeks & 2 weeks & 4 weeks & 8 weeks & 2 weeks & 4 weeks & 8 weeks \\
\hline $\mathrm{CH} 1$ & -0.09 & -0.14 & -0.17 & -0.35 & -0.41 & -0.46 & -0.45 & -0.52 & -0.56 \\
\hline $\mathrm{CH} 2$ & -0.10 & -0.15 & -0.19 & -0.37 & -0.41 & -0.45 & -0.48 & -0.52 & -0.53 \\
\hline $\mathrm{CH} 3$ & -0.12 & -0.16 & -0.19 & -0.39 & -0.41 & -0.44 & -0.50 & -0.51 & -0.50 \\
\hline $\mathrm{CH} 4$ & -0.14 & -0.17 & -0.19 & -0.41 & -0.41 & -0.43 & -0.51 & -0.50 & -0.48 \\
\hline
\end{tabular}

climatology for USDM changes greater than or equal to two categories and in some cases actually indicate a reduced risk for drought development. Much higher RCI-based probabilities occur, however, for one-category USDM changes, especially for longer 4- and 8-week periods. The smaller improvements compared to climatology are partially due to the propensity for this region to experience frequent wetting/drying cycles during the growing season. Short-term dry spells accompanied by high temperatures can lead to the development of large negative RCI values indicative of rapidly deteriorating conditions; however, heavy rainfall associated with mesoscale convective systems often prevents further drought intensification. In addition, Anderson et al. (2013) have shown that the annual ET cycle is narrower in this part of the United States where the vegetation cycle is intensively managed. Thus, in addition to variations in soil moisture status, ET anomalies are likely influenced by changes in crop emergence and growth rate that may not be related to changes in soil moisture. Phenology-based timing adjustments to the normal curves used to compute the ESI anomalies may improve the information content within agricultural areas dominated by corn and soybean cultivation. Though some of the negative RCI values likely represent false alarms due to these complications, the local rainfall climatology and the conservative nature of the USDM response to rapid changes in moisture stress also contribute to the lower RCI probabilities.

\section{d. RCI-USDM change correlations}

The relationship between the RCI and USDM analyses was further investigated by computing the correlation between the maximum value of the RCI at the end of each rapid change event and the associated increase in the USDM severity from the beginning of a given event until 2, 4, or 8 weeks after an event ended. The correlations were computed separately for each grid point and RCI variable using data from all rapid change events during 2000-12. Figure 10 shows the correlations between each RCI variable and the maximum increase in drought severity from the beginning of an event until 2 weeks after the event ends. The average correlation for the western, eastern, and central U.S. "core" regions denoted in Fig. 10a are shown in Table 1. Because the 2-, 4-, and 8-week correlations have similar spatial characteristics, for brevity, only the average correlations for the 4- and 8-week periods are shown in Tables 2 and 3, respectively.

Overall, each of the RCI variables exhibits a similar spatial structure, with the highest correlations occurring in the south-central United States (Fig. 10). This spatial distribution is consistent with the higher probability ratios shown in section $3 \mathrm{~b}$. The large negative correlations across the eastern two-thirds of the United States reveal that a close correspondence exists between the RCI magnitude and drought intensification in highly vegetated areas. Average correlations across the eastern and central regions are generally between -0.40 and -0.55 at 2 weeks and then decrease slightly by 4 and 8 weeks (Tables 1-3). Across the western United States, however, much lower correlations occur within areas containing lower vegetation cover fractions. As discussed in section $3 \mathrm{~b}$, the poor performance of the $\mathrm{RCI}$ in these areas is partially due to a reduced sensitivity of the

TABLE 2. As in Table 1, but for correlations computed from $t_{\text {beg }}$ to $t_{\text {end }}+4$ weeks.

\begin{tabular}{|c|c|c|c|c|c|c|c|c|c|}
\hline & \multicolumn{3}{|c|}{ Western United States } & \multicolumn{3}{|c|}{ Eastern United States } & \multicolumn{3}{|c|}{ Central U.S. core area } \\
\hline & 2 weeks & 4 weeks & 8 weeks & 2 weeks & 4 weeks & 8 weeks & 2 weeks & 4 weeks & 8 weeks \\
\hline$\overline{\mathrm{CH} 1}$ & -0.08 & -0.13 & -0.14 & -0.34 & -0.39 & -0.41 & -0.45 & -0.50 & -0.51 \\
\hline $\mathrm{CH} 2$ & -0.09 & -0.14 & -0.17 & -0.34 & -0.39 & -0.41 & -0.46 & -0.50 & -0.50 \\
\hline $\mathrm{CH} 3$ & -0.10 & -0.15 & -0.17 & -0.36 & -0.39 & -0.40 & -0.48 & -0.49 & -0.48 \\
\hline $\mathrm{CH} 4$ & -0.12 & -0.16 & -0.16 & -0.37 & -0.39 & -0.40 & -0.48 & -0.48 & -0.46 \\
\hline
\end{tabular}


TABLE 3. As in Table 1, but for correlations computed from $t_{\mathrm{beg}}$ to $t_{\mathrm{end}}+8$ weeks.

\begin{tabular}{|c|c|c|c|c|c|c|c|c|c|}
\hline & \multicolumn{3}{|c|}{ Western United States } & \multicolumn{3}{|c|}{ Eastern United States } & \multicolumn{3}{|c|}{ Central U.S. core area } \\
\hline & 2 weeks & 4 weeks & 8 weeks & 2 weeks & 4 weeks & 8 weeks & 2 weeks & 4 weeks & 8 weeks \\
\hline $\mathrm{CH} 1$ & -0.08 & -0.11 & -0.11 & -0.30 & -0.34 & -0.34 & -0.42 & -0.45 & -0.43 \\
\hline $\mathrm{CH} 2$ & -0.08 & -0.12 & -0.14 & -0.30 & -0.34 & -0.35 & -0.43 & -0.45 & -0.43 \\
\hline $\mathrm{CH} 3$ & -0.08 & -0.12 & -0.14 & -0.31 & -0.34 & -0.35 & -0.44 & -0.45 & -0.43 \\
\hline $\mathrm{CH} 4$ & -0.09 & -0.13 & -0.14 & -0.31 & -0.33 & -0.34 & -0.43 & -0.43 & -0.41 \\
\hline
\end{tabular}

ALEXI model to changes in ET in arid areas where ET is intrinsically low. Indeed, higher correlations are present within many of the more heavily forested areas across the western United States, such as over the northern Rocky Mountains and along the Mogollon Rim in Arizona. Comparison of the RCI variables shows similar correlations at 4 and 8 weeks, with larger differences occurring in the 2-week correlations (Tables 1-3). For most of the United States, the largest correlations are found in the RCI variables based on the 8-week $\triangle \mathrm{ESI}$ composites, although in the central United States, large correlations are also evident for shorter composite periods if longer differencing intervals are used (e.g., the RCI_CH4_2WK variable). These results are opposite those found for the probabilities, where the shortest composite and differencing intervals generally had a higher probability of drought intensification. The lower correlations for the shorter RCI variables may be due to their greater sensitivity to short-term moisture fluctuations that can lead to large $\Delta$ ESI anomalies that do not have sufficient time to develop into more severe drought conditions because of adequate rainfall in subsequent weeks.

\section{Conclusions and discussion}

This study examined the ability of rapid changes in the TIR-based ESI drought product to provide early warning of an increased risk for drought intensification across the United States during the growing season. A new RCI metric encapsulating the accumulated magnitude of unusually rapid changes in ET as depicted by large $\Delta \mathrm{ESI}$ anomalies was developed and compared to weekly drought severity analyses from the USDM. The RCI can be used to highlight areas experiencing either rapid increases or rapid decreases in moisture stress; however, the primary focus of this study is on its drought early warning capabilities. Because response times to changing moisture stress vary with the ESI composite period length and time differencing interval, individual RCI values were computed for each $\triangle \mathrm{ESI}$ variable using data from 2000 to 2012.

Overall, the results revealed that the RCI variables provide useful drought early warning capabilities that could be used to alert vulnerable stakeholders of an increased potential for drought development over subseasonal time scales. Two case study analyses showed that the initial appearance of negative RCI values preceded the introduction of severe-to-exceptional drought in the USDM by more than 4 weeks. To further assess the predictive ability of the RCI, drought intensification probabilities were computed for different lead times and intensification changes as a function of the RCI magnitude. Compared to the baseline USDM intensification probabilities, the RCI-derived probabilities often indicate a much higher risk for drought development that increases greatly as the RCI becomes more negative. The highest probabilities encompass much of the central and eastern United States, with lower probabilities in the western United States. When the RCI is strongly negative, many areas are characterized by intensification probabilities that are several times higher than the baseline climatology. The probabilities generally increase for larger USDM changes occurring over longer time periods, with the greatest enhancement over climatology within regions most susceptible to rapid drought development. Though all $12 \mathrm{RCI}$ variables were well correlated with changes in the USDM depiction, those variables computed using shorter ESI composite and differencing intervals generally contained the highest probabilities.

Future work will explore alternative RCI formulations that address the needs of specific stakeholder groups, such as ranchers and farmers across the central and eastern United States. Studies will be undertaken to assess how these and other socioeconomic groups respond to drought onset and intensification when they have access to early warning tools that can potentially be used to lessen the adverse effects of drought. Flash droughts may be especially disruptive because there is less time for stakeholders to respond to changing conditions; thus, improved early warning would be especially useful in those situations. To better capture local and seasonal variations in vegetation emergence and growth rates, it may be advantageous to use a start date that varies with season and location. The incorporation of vegetation cover fraction anomalies or process-based models into the RCI formulation would help remove 
change signals that are due to delays in vegetation growth rather than to increasing drought stress. Other studies will seek to develop synergistic methods for combining drought early warning signals from the ESI and other drought indicators, such as SPI and NLDAS soil moisture anomalies. A blended approach may improve the robustness and accuracy of the RCI drought early warning signals by providing additional data masks that can be used to identify areas susceptible to rapid drought development. Finally, other studies will be used to explore optimal ways to combine the RCI-based drought intensification probabilities to create weekly maps displaying the likelihood of drought development over different time periods based on current conditions. Further refinements could be made to these drought forecasts by combining this information with weekly-to-monthly temperature and rainfall forecasts.

Acknowledgments. This work was supported by funds provided by the NOAA Climate Program Office under Grant GC09-236. Special thanks are given to Brad Pierce (NOAA/ASPB) and Sharon Nebuda (CIMSS/University of Wisconsin-Madison) for their IDL programming assistance.

\section{REFERENCES}

Allen, R. G., L. S. Pereira, D. Raes, and M. Smith, 1998: Crop evapotranspiration: Guidelines for computing crop water requirements. FAO Irrigation and Drainage Paper 56, FAO, Rome, Italy, 300 pp. [Available online at www.fao.org/docrep/ x0490e/x0490e00.htm.]

Anderson, M. C., J. M. Norman, G. R. Diak, W. P. Kustas, and J. R. Mecikalski, 1997: A two-source time-integrated model for estimating surface fluxes using thermal infrared remote sensing. Remote Sens. Environ., 60, 195-216, doi:10.1016/ S0034-4257(96)00215-5.

— W. P. Kustas, and J. M. Norman, 2007a: Upscaling flux observations from local to continental scales using thermal remote sensing. Agron. J., 99, 240-254, doi:10.2134/agronj2005.0096S.

_ J. M. Norman, J. R. Mecikalski, J. A. Otkin, and W. P. Kustas, 2007b: A climatological study of evapotranspiration and moisture stress across the continental U.S. based on thermal remote sensing: 1. Model formulation. J. Geophys. Res., 112, D10117, doi:10.1029/2006JD007506.

,,,,---- and,$- 2007 \mathrm{c}$ : A climatological study of evapotranspiration and moisture stress across the continental U.S. based on thermal remote sensing: 2. Surface moisture climatology. J. Geophys. Res., 112, D11112, doi:10.1029/ 2006 JD007507.

— C. Hain, B. Wardlow, A. Pimstein, J. R. Mecikalski, and W. P. Kustas, 2011: Evaluation of drought indices based on thermal remote sensing and evapotranspiration over the continental United States. J. Climate, 24, 2025-2044, doi:10.1175/ 2010JCLI3812.1.

,-- J. A. Otkin, X. Zhan, K. Mo, M. Svoboda, B. Wardlow, and A. Pimstein, 2013: An intercomparison of drought indicators based on thermal remote sensing and NLDAS simulations. J. Hydrometeor., 14, 1035-1056, doi:10.1175/ JHM-D-12-0140.1.

Barnabás, B., K. Jäger, and A. Fehér, 2008: The effect of drought and heat stress on reproductive processes in cereals. Plant Cell Environ., 31, 11-38.

Blunden, J., and D. S. Arndt, Eds., 2012: State of the Climate in 2011. Bull. Amer. Meteor. Soc., 93, S1-S264, doi:10.1175/ 2012BAMSStateoftheClimate.1.

Brown, J. F., B. D. Wardlow, T. Tadesse, M. J. Hayes, and B. C. Reed, 2008: The Vegetation Drought Response Index (VegDRI): A new integrated approach for monitoring drought stress in vegetation. GISci. Remote Sens., 45, 16-46, doi:10.2747/ 1548-1603.45.1.16.

Ciais, P., and Coauthors, 2005: Europe-wide reduction in primary productivity caused by heat and drought in 2003. Nature, 437, 529-533, doi:10.1038/nature03972.

Guo, Z., and P. A. Dirmeyer, 2013: Interannual variability of landatmosphere coupling strength. J. Hydrometeor., 14, 1636-1646, doi:10.1175/JHM-D-12-0171.1.

Higgins, R. W., W. Shi, E. Yarosh, and R. Joyce, 2000: Improved United States precipitation quality control system and analysis. NCEP/Climate Prediction Center Atlas 7, 40 pp.

Kebede, H., D. K. Fisher, and L. D. Young, 2012: Determination of moisture deficit and heat stress tolerance in corn using physiological measurements and a low-cost microcontroller-based monitoring system. J. Agron. Crop Sci., 198, 118-129, doi:10.1111/ j.1439-037X.2011.00493.x.

Kogan, F. N., 1990: Remote sensing of weather impacts on vegetation in non-homogeneous areas. Int. J. Remote Sens., 11, 1405-1419, doi:10.1080/01431169008955102.

Li, Y. P., W. Ye, M. Wang, and X. D. Yan, 2009: Climate change and drought: A risk assessment of crop-yield impacts. Climate Res., 39, 31-46, doi:10.3354/cr00797.

Lott, N., and T. Ross, 2006: Tracking and evaluating U.S. billion dollar weather disasters, 1980-2005. Preprints, AMS Forum: Environmental Risk and Impacts on Society: Successes and Challenges, Atlanta, GA, Amer. Meteor. Soc., 1.2. [Available online at http://ams.confex.com/ams/pdfpapers/100686.pdf.]

Lyon, B., M. A. Bell, M. K. Tippett, A. Kumar, M. P. Hoerling, X.-W. Quan, and H. Wang, 2012: Baseline probabilities for the seasonal prediction of meteorological drought. J. Appl. Meteor. Climatol., 51, 1222-1237, doi:10.1175/JAMC-D-11-0132.1.

McKee, T. B., N. J. Doesken, and J. Kleist, 1993: The relationship of drought frequency and duration to time scale. Proc. Eighth Conf. on Applied Climatology, Anaheim, CA, Amer. Meteor. Soc., 179-184.

,-- , and ——, 1995: Drought monitoring with multiple time scales. Proc. Ninth Conf. on Applied Climatology, Dallas, TX, Amer. Meteor. Soc., 233-236.

McNaughton, K. G., and T. W. Spriggs, 1986: A mixed-layer model for regional evaporation. Bound.-Layer Meteor., 74, 262-288, doi:10.1007/BF00122381.

Mecikalski, J. M., G. R. Diak, M. C. Anderson, and J. M. Norman, 1999: Estimating fluxes on continental scales using remotely sensed data in an atmospheric-land exchange model. J. Appl. Meteor., 38, 1352-1369, doi:10.1175/1520-0450(1999)038<1352: EFOCSU $>2.0 . \mathrm{CO} ; 2$.

Mesinger, F., and Coauthors, 2006: North American Regional Reanalysis. Bull. Amer. Meteor. Soc., 87, 343-360, doi:10.1175/ BAMS-87-3-343.

Mishra, V. R., and A. K. Desai, 2005: Drought forecasting using stochastic models. Stochastic Environ. Res. Risk Assess., 19, 326-339, doi:10.1007/s00477-005-0238-4. 
, and K. Cherkauer, 2010: Retrospective droughts in the crop growing season: Implications to corn and soybean yield in the Midwestern United States. Agric. For. Meteor., 150, 1030 1045, doi:10.1016/j.agrformet.2010.04.002.

Mittler, R., 2006: Abiotic stress, the field environment and stress combination. Trends Plant Sci., 11, 15-19, doi:10.1016/ j.tplants.2005.11.002.

Mo, K., 2008: Model-based drought indices over the United States. J. Hydrometeor., 9, 1212-1230, doi:10.1175/2008JHM1002.1.

Moran, M. S., 2003: Thermal infrared measurement as an indicator of plant ecosystem health. Thermal Remote Sensing in Land Surface Processes, D. A. Quattrochi and J. Luvall, Eds., Taylor and Francis, 257-282.

Mozny, M., M. Trnka, Z. Zalud, P. Hlavinka, J. Nekovar, V. Potop, and M. Virag, 2012: Use of a soil moisture network for drought monitoring in the Czech Republic. Theor. Appl. Climatol., 107, 99-111, doi:10.1007/s00704-011-0460-6.

Myneni, R. B., and Coauthors, 2002: Global products of vegetation leaf area and fraction absorbed by PAR from year of MODIS data. Remote Sens. Environ., 83, 214-231, doi:10.1016/ S0034-4257(02)00074-3.

Norman, J. M., W. P. Kustas, and K. S. Humes, 1995: A two-source approach for estimating soil and vegetation energy fluxes from observations of directional radiometric surface temperature. Agric. For. Meteor., 77, 263-292, doi:10.1016/ 0168-1923(95)02265-Y.

Otkin, J. A., M. C. Anderson, J. R. Mecikalski, and G. R. Diak, 2005: Validation of GOES-based insolation estimates using data from the U.S. Climate Reference Network. J. Hydrometeor., 6, 460-475, doi:10.1175/JHM440.1.

,-- C. Hain, I. Mladenova, J. Basara, and M. Svoboda, 2013: Examining flash drought development using the thermal infrared based evaporative stress index. J. Hydrometeor., 14, 1057-1074, doi:10.1175/JHM-D-12-0144.1.

Palmer, W. C., 1965: Meteorological drought. U.S. Weather Bureau Research Paper 45, NOAA, Silver Spring, MD, 58 pp. [Available online at www.ncdc.noaa.gov/temp-and-precip/ drought/docs/palmer.pdf.]

Pradhan, G. P., P. V. V. Prasad, A. K. Fritz, M. B. Kirkham, and B. S. Gill, 2012: Response of Aegilops species to drought stress during reproductive stages of development. Funct. Plant Biol., 39, 51-59, doi:10.1071/FP11171.

Prasad, P. V. V., S. R. Pisipati, I. Momcilivic, and Z. Ristic, 2011: Independent and combined effects of high temperature and drought stress during grain filling on plant yield and chloroplast EF-Tu expression in spring wheat. J. Agron. Crop Sci., 197, 430 441, doi:10.1111/j.1439-037X.2011.00477.x.
Rotter, R., and S. C. van de Geijn, 1999: Climate change effects on plant growth, crop yield, and livestock. Climatic Change, 43, 651-681, doi:10.1023/A:1005541132734.

Saini, H. S., and M. E. Westgate, 1999: Reproductive development in grain crops during drought. Adv. Agron., 68, 59-96, doi:10.1016/S0065-2113(08)60843-3.

Sen, Z., and V. K. Boken, 2005: Techniques to predict agricultural droughts. Monitoring and Predicting Agricultural Drought, V. K. Boken, A. P. Cracknell, and R. L. Heathcote, Eds., Oxford University Press, 40-54.

Sun, L., S. W. Mitchell, and A. Davidson, 2012: Multiple drought indices for agricultural drought risk assessment on the Canadian prairies. Int. J. Climatol., 32, 1628-1639, doi:10.1002/joc.2385.

Svoboda, M., and Coauthors, 2002: The Drought Monitor. Bull. Amer. Meteor. Soc., 83, 1181-1190.

Swain, S., B. D. Wardlow, S. Narumalani, T. Tadesse, and K. Callahan, 2011: Assessment of vegetation response to drought in Nebraska using Terra-MODIS land surface temperature and Normalized Difference Vegetation Index. GISci. Remote Sens., 48, 432-455, doi:10.2747/1548-1603.48.3.432.

USDA, 2012: Cattle inventory report. USDA Doc., 13 pp. [Available online at http://usda01.library.cornell.edu/usda/nass/Catt// 2010s/2012/Catt-01-27-2012.pdf.]

_ 2013: Crop production 2012 summary. USDA Doc., 95 pp. [Available online at http://usda01.library.cornell.edu/usda/ nass/CropProdSu/2010s/2013/CropProdSu-01-11-2013.pdf.]

Vicente-Serrano, S. M., S. Beguería, and J. I. López-Moreno, 2010: A multiscalar drought index sensitive to global warming: The standardized precipitation evapotranspiration index. J. Climate, 23, 1696-1718, doi:10.1175/2009JCLI2909.1.

Wilhite, D. A., and R. S. Pulwarty, 2005: Drought and water crises: Lessons learned and the road ahead. Drought and Water Crises: Science, Technology and Management Issues, D. A. Wilhite, Ed., Taylor and Francis, 389-398.

$\longrightarrow$, M. J. Hayes, C. L. Knutson, and K. H. Smith, 2000: Planning for drought: Moving from crisis to risk management. J. Amer. Water Resour. Assoc., 36, 697-710, doi:10.1111/ j.1752-1688.2000.tb04299.x.

Xia, Y., M. B. Ek, H. Wei, and J. Meng, 2012a: Comparative analysis of relationships between NLDAS-2 forcings and model outputs. Hydrol. Processes, 26, 467-474, doi:10.1002/ hyp. 8240 .

, and Coauthors, 2012b: Continental-scale water and energy flux analysis and validation of the North American Land Data Assimilation System project phase 2 (NLDAS-2): 1. Intercomparison and application of model products. J. Geophys. Res., 117, D03109, doi:10.1029/2011JD016048. 